1 2 3

\title{
A copula-based fuzzy interval-random programming approach for planning water-energy nexus system under uncertainty
}

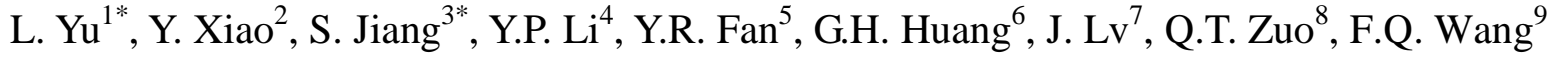 \\ 1* (Corresponding Author) School of Water Conservancy Engineering, Zhengzhou University, Zhengzhou
} 450001, China; Zhengzhou Key Laboratory of Water Resource and Environment, Zhengzhou, 450001, China; Henan Key Laboratory of Groundwater Pollution Prevention and Rehabilitation, Zhengzhou, 450001, China; E-mail: yulei2018@zzu.edu.cn

${ }^{2}$ School of Water Conservancy Engineering, Zhengzhou University, Zhengzhou 450001, China; E-mail: xiaoyaocs@163.com

$3^{*}$ (Corresponding Author) Department of water resources, China Institute of Water Resources and Hydropower Research, Beijing 100038, China; E-mail: jiangs@iwhr.com

${ }^{4}$ School of Environment, Beijing Normal University, Beijing 100875, China; E-mail: yongping.li@iseis.org

${ }^{5}$ Department of Civil and Environmental Engineering, Brunel University London, Uxbridge, UB8 3PH, United Kingdom; E-mail: yurui.fan@gmail.com

${ }^{6}$ Institute for Energy, Environment and Sustainable Communities, University of Regina, Regina, Sask. S4S 7H9, Canada; E-mail: gordon.huang@uregina.ca

${ }^{7}$ Sino-Canada Energy and Environmental Research Center, North China Electric Power University, Beijing 102206, China; E-mail: 291697439@qq.com

${ }^{8}$ School of Water Conservancy Engineering, Zhengzhou University, Zhengzhou 450001, China; E-mail: zuoqt@zzu.edu.cn

${ }^{9}$ Department of Water Conservancy Engineering, North China University of Water Resources and Electric Power, Zhengzhou 450046, China; E-mail: wangfuqiang@ncwu.edu.cn 
Keywords: copula, interaction, joint risk, uncertainty, water-energy nexus system 


\section{Introduction}

\subsection{Importance}

Water and energy, the world's two most critical resources, are gaining international attention from both the general public and the academia [1]. Water and energy are closely linked. The supply, transportation and treatment of water resources need to consume a large amount of energy, while the whole process of energy production from mineral exploitation to electricity generation needs to be completed under the action of water cleaning, cooling and conduction [2]. Water and energy are interdependent and restrict each other, which has become major restraints to urban development [3].China, a largest developing country around the world, occupies $21 \%$ of the world's energy consumption and holds $6 \%$ of the global fresh water sources [4]. The contradictions among water, energy, air pollution and carbon dioxide $\left(\mathrm{CO}_{2}\right)$ emissions are increasingly deteriorative. Moreover, the primary energy bases in China are among the most water-stressed area of the country [5]. Such mismatched geographical space further aggravates the challenge between water shortage and energy security. Although several polices such as " 3 Red lines" and "Water allocation plan for coal bases" were enacted to reduce water utilization, improve water efficiency and reduce sewage water discharges in the coal sector, particularly for further managing future coal-fired power plants in water-scarce regions [6]. However, in real-world water-energy nexus (WEN) problems, water and energy resources are associated with social, economic, managerial and environmental limitations [7]. Above of which force researchers to propose effective strategies toward the energy system's water utilization in a mutually-beneficial manner between economic development and environmental mitigation.

\subsection{Literature review}

Previously, numerous studies were focused on quantitatively analyzing WEN system. For example, Al-Ansari et al. [8] adopted a life cycle assessment (LCA) approach to assess the nexus of water-energy-food (WEF) in food production systems. Wang and Chen [9] developed a multi-regional network model for planning the WEN of Beijing-Tianjin-Hebei urban agglomeration. Chhipi-Shrestha et al. [10] used a system dynamic modelling (SDM) to recognize 
key factors for the urban water system in Penticton. Khan et al. [11] formulated an integrated agent-based modelling ABM-SWAT (soil and water-assessment tool) model for analyzing the water-energy-food-environment (WEFE) nexus system management in transboundary river basins. Summarily, the above studies are mainly focused on dealing with WEN problems when their system components were deterministic. However, some coefficients are not obtained as deterministic due to the inaccuracy of empirical observations and estimations [12]. Thus, it is of indispensability to exploit more robust optimization techiques for planning WEN corresponding to the associated complexities and uncertainties [13].

Recently, lots of efforts were made in WEN for dealing with uncertainties such as integrated energy system modelling (IESM), multi-objective programming (MOP), two-level programming (TLP), system dynamics approach (SDA). For example, Zhang and Vesselinov [14] proposed a bi-level model for handling the tradeoffs in WEN problems. Bieber et al. [15] developed an integrated modelling for the WEF nexus system, where ABM was used for simulating varied resource demands and scenario-based approaches were used for presenting different policies. $\mathrm{Li}$ et al. [16] used an incorporated multi-objective programming method to planning the agricultural WEF, where contradictions among water, energy, food and land are handled. Feng et al. [17] used the system dynamics approach for modeling the nexus across water, power and environment in Hehuang Region, China. In general, the above studies mainly focused on handling WEN tradeoffs through using the modeled scenarios among different policies or varied views of decision makers, and overall satisfaction of the two-level decision makers [18]. However, few of them are specialized in analyzing the intricate and complex interactions of the WEN system. For a real-world WEN system, it includes two subsystems (water subsystem and energy subsystem), and each contains multiple layers and components. Every component in each subsystem can result in changed influence on the other subsystem and pose joint shortage risk between water and energy [19]. Copula approach has its effectiveness in reflecting joint-violation risk through modeling multivariate joint distributions [20].

\subsection{Contribution}


This study aims to propose a copula-based fuzzy interval-random programming (CFIP) approach for multi-uncertainty reflection by combining copula-based random programming (CRP), interval-parameter programming (IPP) and fuzzy possibilistic programming (FPP). Compared to the deterministic quantitatively analysis methods in Al-Ansari et al. [8], Wang and Chen [9], Chhipi-Shrestha et al. [10] and Khan et al. [11], CFIP can handle complexities and uncertainties existing in WEN management problems. In comparison with the inexact optimization methods in Zhang and Vesselinov [14], Bieber et al. [15], Li et al. [16], and Feng et al. [17], CFIP can not only deal with uncertainties presented by the interval and fuzzy information but also tackle the random water resources availability and electricity demand as well as the correlative system joint-risk. Summarily, CFIP combines the superiority of CRP, IPP and FPP into one framework, which can efficaciously: (a) deal with the uncertainties expressed as random variables, interval values and fuzzy sets as well as their combinations (i.e. interval-fuzzy modulus and interval-random variables); (b) reveal the water-shortage risk, electricity-shortage risk as their correlated joint-shortage risk. Then, a CFIP-WEN model is developed and then applied to the WEN system of Henan Province, China. In the CFIP-WEN model, four classes of copulas (i.e. Clayton, Frank, Gumbel and Student's t copulas), five scenarios with different groups of water resources availability and electricity consumption, four $\lambda$ levels corresponding to decision makers' different necessity degrees of the system cost are considered. Results will help decision makers: (a) identify the desired electricity-supply patterns under the conflicts among economic objective, water resources shortage and electricity demand as well as environmental requirement; (b) analyze interactions between water resources availability and electricity consumption, and disclose their joint risk on WEN system associated with different scenarios.

\section{Methodology}

CRP has advantages of capturing the dependence of bivariate or multivariate random variables and binding disparate univariate marginal distributions together through constructing their joint distribution based on a copula function [21]. According to Charnes and Cooper [22], Chen et al. [23], Simic and Dabic-Ostojic [24], a generic CRP model can be depicted as

$$
\operatorname{Min} E=\sum_{j=1}^{n} c_{j} x_{j}
$$


subject to:

$$
\begin{aligned}
& \sum_{j=1}^{n} a_{i j} x_{j} \leq b_{i}^{p_{i}}, i=1,2, \ldots, k \\
& C\left(1-p_{1}, 1-p_{2}, \ldots, 1-p_{k}\right)=1-p \\
& \sum_{j=1}^{n} a_{i j} x_{j} \leq b_{i}, i=k+1, k+2, \ldots, m \\
& x_{j} \geq 0, j=1,2, \ldots, n
\end{aligned}
$$

where $x_{j}$ are decision variables; $a_{i j}$ and $b_{i}$ are coefficients; $b_{i}^{p_{i}}$ are random variables; $C$ is the determinate copula; $p_{i}(i=1,2, \ldots, k)$ are constraint-violation levels; $b_{i}^{p_{i}}=F_{i}^{-1}\left(p_{i}\right)$.

For a real-world WEN system, some economic parameters are affected by the socio-economic, political, legislation and technical factors, which can hard to be achieved as stochastic variables but can be presented as interval values through using the IPP technique [25]. Some imprecise data can rarely be achieved as randomness and interval but can be presented by fuzzy sets [26]. Through introducing IPP and FPP into CRP, a CFIP model can be formulated as:

$$
\operatorname{Min} \underset{\sim}{E^{ \pm}}=\sum_{j=1}^{n} \underset{\sim}{\underset{c}{c_{j}^{ \pm}}} x_{j}^{ \pm}
$$

subject to:

$$
\begin{aligned}
& \sum_{j=1}^{n} a_{i j}^{ \pm} x_{j}^{ \pm} \leq b_{i}^{\left(p_{i}\right) \pm}, i=1,2, \ldots, k \\
& C\left(1-p_{1}, 1-p_{2}, \ldots, 1-p_{k}\right)=1-p \\
& \sum_{j=1}^{n} a_{i j}^{ \pm} x_{j}^{ \pm} \leq b_{i}^{ \pm}, i=k+1, k+2, \ldots, m \\
& x_{j}^{ \pm} \geq 0, j=1,2, \ldots, n
\end{aligned}
$$

where $a_{i j}^{ \pm} \in\left\{R^{ \pm}\right\}^{m \times n}, b_{i}^{ \pm} \in\left\{R^{ \pm}\right\}^{m \times 1}, c_{\sim j}^{ \pm} \in\left\{R^{ \pm}\right\}^{1 \times n}, x_{j}^{ \pm} \in\left\{R^{ \pm}\right\}^{n \times 1} ; R^{ \pm}$mean interval numbers; ${\underset{\sim}{j}}_{j}^{ \pm}$ represent fuzzy-boundary intervals. Based on Inuiguchi and Ramik [27], Model (2) can be converted into: 
subject to:

$$
\begin{aligned}
& \sum_{j=1}^{l} a_{i j}^{ \pm} x_{j}^{ \pm}+\sum_{j=l+1}^{n} a_{i j}^{ \pm} x_{j}^{ \pm} \leq b_{i}^{\left(p_{i}\right) \pm}, i=1,2, \ldots, k \\
& C\left(1-p_{1}, 1-p_{2}, \ldots, 1-p_{k}\right)=1-p \\
& \sum_{j=1}^{l} a_{i j}^{ \pm} x_{j}^{ \pm}+\sum_{j=l+1}^{n} a_{i j}^{ \pm} x_{j}^{ \pm} \leq b_{i}^{ \pm}, i=k+1, k+2, \ldots, m \\
& x_{j}^{ \pm} \geq 0, j=1,2, \ldots, n
\end{aligned}
$$

where $\lambda$ means p-necessity level [28]. In this study, two-step method (TSM) is used for obtaining interval values of the CFIP model (i.e. $f_{\mathrm{opt}}^{ \pm}=\left[f_{\mathrm{opt}}^{-}, f_{\mathrm{opt}}^{+}\right]$and $x_{\mathrm{opt}}^{ \pm}=\left[x_{\mathrm{opt}}^{-}, x_{\mathrm{opt}}^{+}\right]$) under each $p$ level and each $\lambda$ level [29].

\section{Case Study}

Henan Province sits in the central China and covers an area of $167 \times 10^{3} \mathrm{~km}^{2}$. It consists of 17 prefectural-level cities and 1 city administrated by province, as shown in Figure 1. In 2017, the gross domestic product (GDP) and total population of Henan reached to RMB¥ 4,498.82 billion and 108.53 million, respectively. Most rivers in Henan originate from mountainous areas in the west, northwest and southeast, among which 560 rivers covering an area of more than $100 \mathrm{~km}^{2}$. The annual average amounts of water resources reached 40.35 billion $\mathrm{m}^{3}$, ranking $19^{\text {th }}$ in China. However, the per capita water resources were about $383 \mathrm{~m}^{3}$, merely accounting for one-fifth of the national average. The limited water resources and increased water demand are increasingly restricting the sustainable development of Henan Province accompanied with anticipated climate change [30].

Place Figure 1 here 
As a primary agricultural province, agriculture occupies the primary role in the whole water use, followed by the industry, consumption and ecological protection sectors (Figure 2).For Henan Province, several electricity-conversion technologies such as conventional thermal plants (coal-fired power and nature gas-fired power) and renewable-energy based power plants (hydropower, wind, solar and biomass power) are mainly used for satisfying the local electricity demand. Simultaneously, the conversion processes of these facilities also need water in cooling, steam generation, desulfurization and cleaning. In this study, the modeling parameters are presented as interval values, probability distributions, fuzzy sets as well as their correlated dual uncertainties (i.e. interval-fuzzy modulus and interval-random variables). For example, the correlative water-consumption is subjected to a range of factors (i.e. electricity conversion type, cooling mode, as well as other weather conditions) [4]. The pollutant-emission coefficients and other technical parameters (i.e. residual capacity, capacity expansion, service time, energy consumption rate and power consumption rate) are associated with series of factors such as the energy resources type, energy quality, combustion condition and operation condition, as well as other weather conditions [31]. Thus the correlative water-consumption parameters, pollutant-emission coefficients and other technical parameters are expressed as intervals. Economic coefficients which are closely related to the volatility of interest rates, inflation rates and other factors (i.e., energy price, labor fee, and operation condition) are presented as interval-fuzzy modulus with known fuzzy possibility distributions [32]. Water resources availability and electricity demand which are affected by meteorologic, hydrologic and sociometric conditions are presented as interval-random variables [33].

Place Figure 2

Based on the CFIP method, a provincial-scale CFIP-WEN model is formulated for the purpose of minimizing the system cost, which consists of cost of water resources, energy resources, electricity-generation, -import and -transmission as well as contamination controlling. For example, for a real-world WEN system planning issues, the cost of water resources for electricity generation mainly consists of the processes of cooling, boiling and desulfurization as well as others [32]. Energy import cost includes the cost of importing local and adjacent energies during 
The constraints are:

Cost of water resource for electricity generation

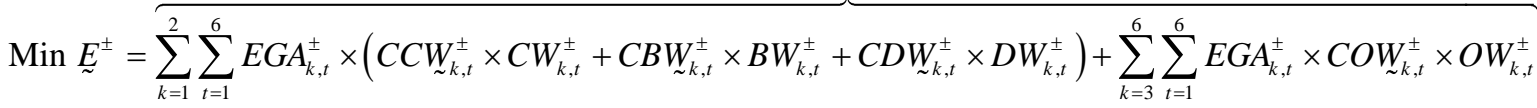

$$
\begin{aligned}
& +\underbrace{\sum_{k=1}^{2} \sum_{t=1}^{6} P E C_{\sim, t}^{ \pm} \times E G A_{k, t}^{ \pm} \times F E_{k, t}^{ \pm}+\sum_{t=1}^{6} P E J_{\sim}^{ \pm} \times P E_{t}^{ \pm}}+\underbrace{\sum_{t}}_{\sum_{k=1}^{6} \sum_{t=1}^{6} E G A_{k, t}^{ \pm} \times C{\underset{\sim}{k, t}}_{t}^{ \pm}} \\
& \text {Cost for importing energy resources and electricity Cost for electricity transmission } \\
& +\underbrace{\sum_{k=1}^{6} \sum_{t=1}^{6}\left(E G A_{k, t}^{ \pm} \times V G{\underset{\sim}{ \pm, t}}_{t}^{ \pm}\right)+\sum_{k=1}^{6} F G C_{\sim k, t}^{ \pm} \times\left(R C_{k, t=0}^{ \pm}+\sum_{t=1}^{6} E C_{k, t}^{ \pm}\right)}_{\text {Cost for electricity generation }}+\underbrace{\sum_{k=1}^{6} \sum_{t=1}^{6}\left(F E C_{\sim, t}^{ \pm} \times Y C_{k, t}^{ \pm}+V E C_{\sim, t}^{ \pm} \times E C_{k, t}^{ \pm}\right)}_{\text {Cost for capacity expansion }} \\
& +\underbrace{\sum_{k=1}^{6} \sum_{t=1}^{6} \sum_{q=1}^{3} E G A_{k, t}^{ \pm} \times\left(3.6 \times C{\underset{\sim t, q}{ \pm}}_{ \pm}^{ \pm}+C{\underset{\sim}{E, q}}_{ \pm}^{ \pm} / S T_{k, t}^{ \pm}-3.6 \times S{\underset{\sim}{t}}_{ \pm}^{ \pm}\right)}_{\text {Cost for pollutant reduction }}+\underbrace{\sum_{k=1}^{\sum_{t=1}^{6}} E G A_{k, t}^{ \pm} \times \delta_{\sim, t}^{ \pm} \times \mu_{k, t}^{ \pm}}_{\text {Cost for } \mathrm{CO}_{2} \text { mitigation }}
\end{aligned}
$$

\section{(1) System joint-risk constraint between water resources availability and electricity demand,} which is used for guaranteeing that each individual chance constraint should be satisfied the acceptable joint-risk of constraint violation.

$$
C\left(1-p_{1}, 1-p_{2}\right)=1-p
$$

(2) Water resource availability constraint, which is established to ensure that the amount of water consumption must be not less than the total available water resources amounts.

$$
\operatorname{Pr}\left\{\sum_{k=1}^{2} E G A_{k, t}^{ \pm} \times\left(C W_{k, t}^{ \pm}+B W_{k, t}^{ \pm}+D W_{k, t}^{ \pm}\right)+\sum_{k=3}^{6} E G A_{k, t}^{ \pm} \times O W_{k, t}^{ \pm} \leq T A W_{t}^{ \pm}\right\} \geq 1-p_{1}
$$

(3) Constraint for water demand-supply, which is formulated to ensure that the total water 
consumption (i.e. cooling water, boiler water, desulfurization water and other water) should not be less than the amount of water resources demands.

$$
\sum_{k=1}^{2} E G A_{k, t}^{ \pm} \times\left(C W_{k, t}^{ \pm}+B W_{k, t}^{ \pm}+D W_{k, t}^{ \pm}\right)+\sum_{k=3}^{6} E G A_{k, t}^{ \pm} \times O W_{k, t}^{ \pm} \geq W D B_{t}^{ \pm}
$$

(4) Energy resource availability constraint: This constraint is established to ensure that the amount of energy utilization must be not less than the total available energy amounts.

$$
E G A_{k, t}^{ \pm} \times F E_{k, t}^{ \pm} \leq A R_{k, t}^{ \pm}
$$

(5) Capacity limitation constraints: These constraints are established to ensure that the capacity will satisfy the demand of electricity from a long-term planning point of view. The related optimization analysis will require the use of integer variables to indicate whether a particular facility development or expansion option needs to be undertaken.

$$
\begin{aligned}
& E G A_{k, t}^{ \pm} \leq\left(R C_{k, t=0}^{ \pm}+\sum_{t^{\prime}=0}^{t-1} E C_{k, t}^{ \pm}\right) \times S T_{k, t}^{ \pm} \\
& Y C_{k, t}^{ \pm}\left\{\begin{array}{l}
=1 ; \quad \text { if capacity expasion is undertaken } \\
=0 ; \quad \text { if otherwise }
\end{array}\right\} \\
& 0 \leq E C_{k, t}^{ \pm} \leq M C_{k, t}^{ \pm} \times Y C_{k, t}^{ \pm}
\end{aligned}
$$

(6) Constraint for electricity demand-supply: These constraints are established to ensure that the total electricity generated from the existing and future expanding capacities, and purchased from other power grids should not be less than the amount of electricity demands.

$$
\operatorname{Pr}\left\{\left(\sum_{k=1}^{6} E G A_{k, t}^{ \pm} \times\left(1-Z L_{k, t}^{ \pm}\right) \times T E_{k, t}^{ \pm}+P E_{t}^{ \pm}\right) \times\left(1-\eta_{t}^{ \pm}\right) \geq E D B_{t}^{ \pm}\right\} \geq 1-p_{2}
$$

(7) Constraint for pollutant and $\mathrm{CO}_{2}$ emissions: These constraints are used for ensuring that the pollutant-emission amounts should be satisfied by the pollutant-emission permits.

$$
\begin{aligned}
& \sum_{k=1}^{6} E G A_{k, t}^{ \pm} \times A M R_{k, t, q}^{ \pm} \leq E S_{t, q}^{ \pm} \\
& \sum_{k=1}^{6} E G A_{k, t}^{ \pm} \times \delta_{k, t}^{ \pm} \times\left(1-C C A_{t}^{ \pm}\right) \leq E S C_{t}^{ \pm}
\end{aligned}
$$

(8) Nonnegative constraints: This constraint assures that only positive electricity-conversion activities are considered in the solution, eliminating infeasibilities while calculating the solution.

$$
E G A_{k, t}^{ \pm}, P E_{t}^{ \pm}, E C_{k, t}^{ \pm} \geq 0
$$




\section{Result Analysis}

Figure 4 presents the electricity-supply schemes under different scenarios. Summarily, the percentage of electricity by coal-fired power would change with the variation of scenarios, which range from $[79.2,80.8] \%(\mathrm{~S} 1)$ to $[81.8,82.6] \%(\mathrm{~S} 5)$. This is because low water-resources availability would force the managers to select more renewable energy-based electricity owing to the consideration of system reliability, economic development and water consumption; conversely, managers would tend to choose more local fossil energy-based electricity under high water-resources availability. Besides, since the renewable energy-based electricity is subject to the capacity limitation of renewable energy resources, the variation of associated electricity-generation would change very little. Figure 5 presents the electricity-generation pattern for each power plant in each year. Generally, the local electricity supply is primarily 
depending on the coal-fired power even having a decreasing trend from [84.1, 85.5] \% to [74.9, 76.5] \% during the planning horizon. Gas-fired power and hydropower would take minor shares for the WEN system while having an increasing tendency. The remaining power plants such as wind power, solar power and biomass power would occupy small contributions for the local electricity-supply because of the limited energy resources, small capacities, and high investment costs.

Place Figures 4 and 5 here

Figure 6 shows the expanded capacities of power conversion facilities in each year. Summarily, the expanded capacity of each power conversion facility in each year would be different. Coal-fired power would have no expansion scheme while wind power and solar power would have high expansion scheme over the planning horizon. For example, the lower bound of expanded capacity for wind power would be $0.68 \mathrm{GW}$ in year 1, $0.68 \mathrm{GW}$ in year 2, $0.69 \mathrm{GW}$ in year 3, $0.60 \mathrm{GW}$ in year $4,0.59 \mathrm{GW}$ in year 5 and $0.59 \mathrm{GW}$ in year 6 , respectively. This is mainly because decision makers would incline to choose more local electricity-generation having low water-consumption and pollutant-discharge. Moreover, energy management decision makers would prefer to developing local renewable energies in order to improve the local power security and promote urban sustainable development in the long run. Figure 7 depicts the imported electricity under different scenarios. Results disclose that the imported electricity would decrease with time, and the imported electricity would decrease from $[176.37,192.66] \times 10^{3} \mathrm{GWh}$ in year 1 to $[175.21,159.70] \times 10^{3} \mathrm{GWh}$ in year 6 under S1. Results also demonstrate that different scenarios would contribute to varied amounts of imported electricity. The variation of imported electricity would change around $16.3 \%$ between S1 and S2 at the end planning horizon.

Place Figures 6 and 7 here

Figure 8 presents the water consumption for each power plant under different scenarios. Generally, interactions of water availability and electricity demand would change the total water 
consumption, and the total water consumption would approximately increase by [194.9, 203.4] $\times 10^{6} \mathrm{~m}^{3}$ from $\mathrm{S} 1$ to $\mathrm{S} 5$. Results also show that coal-fired power consumes more than $90 \%$ of the water consumption, and the water consumption of coal-fired power would decrease with time owing to the water availability scenarios (e.g., the more available water resources, the higher coal-fired based electricity).Thus, it is of indispensability to exploit more renewable energies having lower water-requirement to balance contradictions of water demand-supply, electricity demand-supply and pollutant mitigation.

Place Figure 8 here

Figure 9 shows the emissions of three air-pollutants (i.e. $\mathrm{SO}_{2}, \mathrm{NO}_{\mathrm{x}}$ and $\mathrm{PM}_{10}$ ) and $\mathrm{CO}_{2}$. Results indicate that different water availability scenarios would affect the electricity-generation pattern and then lead to the variation of pollutant-emission pathway (e.g., the emissions of pollutants would have a downward trend from S5 to S1). Moreover, under S5 (i.e. the water resources availability generates none effects on the coal-fired power), the average amount of $\mathrm{CO}_{2}$ would decrease from $21.63 \times 10^{6}$ tonne (year 1 ) to $21.30 \times 10^{6}$ tonne (year 6). This is mainly attributed to the fact that many efforts such as strict mitigation target, policy stimulation for renewable energy and improvement of pollutant-mitigation efficiency play jointly contributions for reducing pollutants and $\mathrm{CO}_{2}$ emissions. Thus, some new technologies (e.g., wind power and solar power) that can both meet electricity-demand and reduce pollutant emissions should be further adopted.

Place Figure 9 here

Uncertainties existed in modeling parameters would lead to varied system costs. As shown in Figure 10 , when $\lambda=1$, system cost would increase by $\$[0.18,0.19] \times 10^{12}$ under $\mathrm{S} 1$ compared to that under S2, while $[194.9,203.4] \times 10^{6} \mathrm{~m}^{3}$ of water were saved. It is mainly because a high water-resources availability violation-risk equivalent to an increased coal-fired power generation reliability, leading to a low system cost; while renewable-energy based and extra electricity from 
other power grids become of indispensability in response to a low water-resources availability violation-risk, thus resulting in a high system cost. Moreover, different $\lambda$ levels correspond to decision makers' different necessity degrees of the system cost, thus leading to changed system costs. For instance, the system cost would vary from $\$[2.99,3.39] \times 10^{12}(\lambda=1)$ to $\$[3.02,3.42]$ $\times 10^{12}(\lambda=0.65)$ under S1. Thus, there exists a trade-off among system cost, risk-averse attitude of decision-maker and water resources availability.

Place Figure 10 here

\section{Conclusions}

In this study, a CFIP method has been exploited through integration of CRP, IPP and FPP. CFIP can both handle random, interval and interval information and reflect system joint-risk employed to the WEN system of Henan Province, China. Solutions of various copulas associated with different scenarios and necessity degrees are examined in the CFIP-WEN model. CFIP-WEN model has advantages of: (a) disclosing interactions between water resources availability and electricity consumption, and further illustrating their interactive effects on WEN system in association with various scenarios and multiple uncertainties; (b) balancing the conflict among economic objective, water resources shortage and electricity demand, as well as environmental requirement.

Solutions for system cost, electricity-supply pattern, water-allocation pattern, and pollutant-emission associated with various scenarios and multiple uncertainties have been achieved. Results indicate that uncertainties and scenarios employed to water resources, electricity demand and other module parameters can generate prominent impacts on the WEN system. Water resources can restrict the local electricity-generation pattern and then lead to the change of system cost, and the system cost would increase by $\$[0.18,0.19] \times 10^{12}$ under S1 compared to that under $\mathrm{S} 2$, while around $[194.9,203.4] \times 10^{6} \mathrm{~m}^{3}$ of water to be saved. Compared to high water-availability scenario (S5), the share of electricity generated by the coal-fired power can decrease by $[1.8,2.6] \%$ under low water-availability scenario (S1). 


\begin{abstract}
Although CFIP-WEN model has its effectiveness in reflecting the interactions between water resources availability and electricity demand, and providing optimal solutions for WEN management, it neglects the hierarchically conflicting objectives in the WEN system (e.g., the objectives of minimum system cost and minimum water consumption), making the results incapable of presenting the real-world WEN planning issues [40]. Besides, the constraints of the CFIP-WEN model are limited to production-demand relationships, efficiency, storage and operation levels of the electricity-conversion technologies should be further considered in order to improve the robustness of the CFIP-WEN model [41]. In addition, energy- and water-supply security especially for the water-stressed area is an international challenge, some more advanced theory and robust model should be referenced to cope with such increasing energy demand and water shortage [42].
\end{abstract}

\title{
Acknowledgements
}

This research was supported by the National Natural Science Foundation of China (51909239), the Key Research Project of Henan Higher Education Institution (20A570001) and the Postdoctoral Foundation of Henan Province (1901008). The authors are grateful to the editors and the anonymous reviewers for their insightful comments and suggestions. 


\section{References}

[1] Khalkhali M, Westphal K, Mo WW. The water-energy nexus at water supply and its implications on the integrated water and energy management. Science of The Total Environment 2018;636:1257-1267.

[2] Gjorgiev B, Sansavini G. Water-energy nexus: Impact on electrical energy conversion and mitigation by smart water resources management. Energy Conversion and Management 2017;148:1114-1126.

[3] Fan JL, Kong LS, Wang H, Zhang X. A water-energy nexus review from the perspective of urban metabolism. Ecological Modelling 2019;392:128-136.

[4] Lv J, Li YP, Shan BG, Jin SW, Suo C. Planning energy-water nexus system under multiple uncertainties - A case study of Hebei province. Applied Energy 2018;229:389-403.

[5] Li N, Chen WY. Energy-water nexus in China's energy bases: From the Paris agreement to the Well Below 2 Degrees target. Energy 2019;166:277-286.

[6] Qin Y, Curmi E, Kopec GM, Allwood JM, Richards KS. China’s energy-water nexus assessment of the energy sector's compliance with the "3 Red Lines" industrial water policy. Energy Policy 2015;82:131-143.

[7] Cai YP, Cai JY, Xu LY, Tan Q, Xu Q. Integrated risk analysis of water-energy nexus systems based on systems dynamics, orthogonal design and copula analysis. Renewable and Sustainable Energy Reviews 2019;99:125-137.

[8] Al-Ansari T, Korre A, Nie ZG, Shah N. Development of a life cycle assessment tool for the assessment of food production systems within the energy, water and food nexus. Sustainable Production and Consumption 2015;2:52-66.

[9] Wang SG, Chen B. Energy-water nexus of urban agglomeration based on multiregional input-output tables and ecological network analysis: A case study of the Beijing-Tianjin-Hebei region. Applied Energy 2016;178:773-783.

[10] Chhipi-Shrestha G, Hewage K, Sadiq R. Water-energy-carbon nexus modeling for urban water systems: system dynamics approach. Journal of Water Resources Planning and Management 2017;143:04017016.

[11] Khan HF, Yang YCE, Xie H, Ringler C. A coupled modeling framework for sustainable watershed management in transboundary river basins. Hydrology and Earth System Sciences 
2017;21:6275-6288.

[12] Yu L, Li YP, Huang GH. A fuzzy-stochastic simulation-optimization model for planning electric power systems with considering peak-electricity demand: A case study of Qingdao, China. Energy 2016;98:190-203.

[13] Cai XM, Wallington K, Shafiee-Jood M, Marston L. Understanding and managing the food-energy-water nexus - opportunities for water resources research. Advances in Water Resources 2018;111:259-273.

[14] Zhang XD, Vesselinov VV. Energy-water nexus: Balancing the tradeoffs between two-level decision makers. Applied Energy 2016;183:77-87.

[15] Bieber N, Ker JH, Wang XN, Triantafyllidis C, van Dam KH, Koppelaar RHEM, Shah N. Sustainable planning of the energy-water-food nexus using decision making tools. Energy Policy 2018;113:584-607.

[16] Li M, Fu Q, Singh VP, Liu D. An interval multi-objective programming model for irrigation water allocation under uncertainty. Agricultural Water Management 2018;196:24-36.

[17] Feng MY, Liu P, Li ZJ, Zhang JW, Liu DD, Xiong LH. Modeling the nexus across water supply, power generation and environment systems using the system dynamics approach: Hehuang Region, China. Journal of Hydrology 2016;543, Part B:344-359.

[18] Pahl-Wostl C. Governance of the water-energy-food security nexus: A multi-level coordination challenge. Environmental Science \& Policy 2019;92:356-367.

[19] Thiede S, Schönemann M, Kurle D, Herrmann C. Multi-level simulation in manufacturing companies: The water-energy nexus case. Journal of Cleaner Production 2016;139:1118-1127.

[20] Su JX, Furman E. Multiple risk factor dependence structures: Copulas and related properties. Insurance: Mathematics and Economics 2017;74:109-121.

[21] Nelsen RB. An introduction to copulas. New York: Springer, 1999. ISBN 0-387-98623-5.

[22] Charnes A, Cooper WW. Response to decision problems under risk and chance constrained programming: dilemmas in the transitions. Management Science 1983;29(6):750-753.

[23] Chen F, Huang GH, Fan YR, Chen JP. A copula-based fuzzy chance-constrained programming model and its application to electric power generation systems planning. Applied Energy 2017;187:291-309.

[24] Simic V, Dabic-Ostojic S. Interval-parameter chance-constrained programming model for 
uncertainty-based decision making in tire retreading industry. Journal of Cleaner Production 2017;167:1490-1498.

[25] Li YP, Nie S, Huang CZ, McBean EA, Fan YR, Huang GH. An integrated risk analysis method for planning water resource systems to support sustainable development of an arid region. Journal of Environmental Informatics. 2017;29(1):1-15.

[26] Yu L, Li YP, Huang GH. Planning municipal-scale mixed energy system for stimulating renewable energy under multiple uncertainties-The City of Qingdao in Shandong Province, China. Energy 2019;166:1120-1133.

[27] Inuiguchi M, Ramik J. Possibilistic linear programming: a brief review of fuzzy mathematical programming and a comparison stochastic programming inportfolio selection problem. Fuzzy Sets and Systems 2000;111:3-28.

[28] Zhou Y, Li YP, Huang GH, Zhou Y. A robust approach for planning electric power systems associated with environmental policy analysis. Electric Power Systems Research 2013;95:99-111.

[29] Huang GH, Baetz BW, Patry GG. A grey linear programming approach for municipal solid waste management planning under uncertainty. Civil Engineering Systems 1992;9(4):319-335.

[30] Yin YY, Tang QH, Liu XC, Zhang XJ. Water scarcity under various socio-economic pathways and its potential effects on food production in the Yellow River basin. Hydrology and Earth System Sciences 2017;21:791-804.

[31] Li YP, Huang GH. Electric-power systems planning and greenhouse-gas emission management under uncertainty. Energy Conversion and Management 2012;57:173-182.

[32] Liu J, Li YP, Huang GH, Suo C, Yin S. An interval fuzzy-stochastic chance-constrained programming based energy-water nexus model for planning electric power systems. Energies 2017;10(11):1914.

[33] Yu L, Li YP, Huang GH, Fan YR, Nie S. A copula-based flexible-stochastic programming method for planning regional energy system under multiple uncertainties: A case study of the urban agglomeration of Beijing and Tianjin. Applied Energy 2018;210:60-74.

[34] Zhu Y, Li YP, Huang GH. Planning carbon emission trading for Beijing's electric power systems under dual uncertainties. Renewable and Sustainable Energy Reviews 2013;23:113-128. 
[35] Jin SW, Li YP, Xu LP. Development of an integrated model for energy systems planning and carbon dioxide mitigation under uncertainty - Tradeoffs between two-level decision makers. Environmental Research 2018;164:367-378.

[36] The $13^{\text {th }}$ Five-year Energy Development Plan of Henan Province. The People's Government of Henan Province; 2017. Available at: < https://www.henan.gov.cn/2017/05-24/270780.html >.

[37] Henan Provincial Water Resources Bulletin. Henan Provincial Department of Water Resources; 2017. Available at: < http://www.hnsl.gov.cn/gallery/8aa98d9267305a9a0167e45e76825bf5.html >.

[38] Henan Statistical Yearbook. Henan Provincial Bureau of Statistics; 2018. Available at: < http://www.ha.stats.gov.cn/hntj/lib/tjnj/2018/indexch.htm >.

[39] Yu L, Li QW, Jin SW, Chen C, Li YP, Fan YR, Zuo QT. A two-level based copula interval-stochastic programming approach for planning energy-water nexus system management under uncertainty. Journal of Hydrology HYDROL32062R1.

[40] Chen YZ, He L, Li J, Cheng X, Lu HW. An inexact bi-level simulation-optimization model for conjunctive regional renewable energy planning and air pollution control for electric power generation systems. Applied Energy 2016;183:969-983.

[41] Kuang JY, Zhang CH, Sun B. Stochastic dynamic solution for off-design operation optimization of combined cooling, heating, and power systems with energy storage. Applied Thermal Engineering 2019, accept. Available at < https://doi.org/10.1016/j.applthermaleng.2019.114356 >.

[42] Zhang C, Chen XX, Li Y, Ding W, Fu GT. Water-energy-food nexus: Concepts, questions and methodologies. Journal of Cleaner Production 2018;195:625-639. 
1

\title{
A copula-based fuzzy interval-random programming approach for planning water-energy nexus system under uncertainty
}

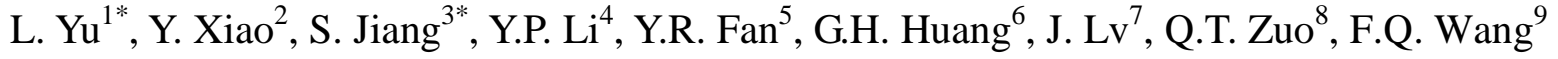 \\ 1* (Corresponding Author) School of Water Conservancy Engineering, Zhengzhou University, Zhengzhou
} 450001, China; Zhengzhou Key Laboratory of Water Resource and Environment, Zhengzhou, 450001, China; Henan Key Laboratory of Groundwater Pollution Prevention and Rehabilitation, Zhengzhou, 450001, China; E-mail: yulei2018@zzu.edu.cn

${ }^{2}$ School of Water Conservancy Engineering, Zhengzhou University, Zhengzhou 450001, China; E-mail: xiaoyaocs@163.com

$3^{*}$ (Corresponding Author) Department of water resources, China Institute of Water Resources and Hydropower Research, Beijing 100038, China; E-mail: jiangs@iwhr.com

${ }^{4}$ School of Environment, Beijing Normal University, Beijing 100875, China; E-mail: yongping.li@iseis.org

${ }^{5}$ Department of Civil and Environmental Engineering, Brunel University London, Uxbridge, UB8 3PH, United Kingdom; E-mail: yurui.fan@gmail.com

${ }^{6}$ Institute for Energy, Environment and Sustainable Communities, University of Regina, Regina, Sask. S4S 7H9, Canada; E-mail: gordon.huang@uregina.ca

${ }^{7}$ Sino-Canada Energy and Environmental Research Center, North China Electric Power University, Beijing 102206, China; E-mail: 291697439@qq.com

${ }^{8}$ School of Water Conservancy Engineering, Zhengzhou University, Zhengzhou 450001, China; E-mail: zuoqt@zzu.edu.cn

${ }^{9}$ Department of Water Conservancy Engineering, North China University of Water Resources and Electric Power, Zhengzhou 450046, China; E-mail: wangfuqiang@ncwu.edu.cn 
Keywords: copula, interaction, joint risk, uncertainty, water-energy nexus system 


\section{Introduction}

\subsection{Importance}

Water and energy, the world's two most critical resources, are gaining international attention from both the general public and the academia [1]. Water and energy are closely linked. The supply, transportation and treatment of water resources need to consume a large amount of energy, while the whole process of energy production from mineral exploitation to electricity generation needs to be completed under the action of water cleaning, cooling and conduction [2]. Water and energy are interdependent and restrict each other, which has become major restraints to urban development [3].China, a largest developing country around the world, occupies $21 \%$ of the world's energy consumption and holds $6 \%$ of the global fresh water sources [4]. The contradictions among water, energy, air pollution and carbon dioxide $\left(\mathrm{CO}_{2}\right)$ emissions are increasingly deteriorative. Moreover, the primary energy bases in China are among the most water-stressed area of the country [5]. Such mismatched geographical space further aggravates the challenge between water shortage and energy security. Although several polices such as " 3 Red lines" and "Water allocation plan for coal bases" were enacted to reduce water utilization, improve water efficiency and reduce sewage water discharges in the coal sector, particularly for further managing future coal-fired power plants in water-scarce regions [6]. However, in real-world water-energy nexus (WEN) problems, water and energy resources are associated with social, economic, managerial and environmental limitations [7]. Above of which force researchers to propose effective strategies toward the energy system's water utilization in a mutually-beneficial manner between economic development and environmental mitigation.

\subsection{Literature review}

Previously, numerous studies were focused on quantitatively analyzing WEN system. For example, Al-Ansari et al. [8] adopted a life cycle assessment (LCA) approach to assess the nexus of water-energy-food (WEF) in food production systems. Wang and Chen [9] developed a multi-regional network model for planning the WEN of Beijing-Tianjin-Hebei urban agglomeration. Chhipi-Shrestha et al. [10] used a system dynamic modelling (SDM) to recognize 
key factors for the urban water system in Penticton. Khan et al. [11] formulated an integrated agent-based modelling ABM-SWAT (soil and water-assessment tool) model for analyzing the water-energy-food-environment (WEFE) nexus system management in transboundary river basins. Summarily, the above studies are mainly focused on dealing with WEN problems when their system components were deterministic. However, some coefficients are not obtained as deterministic due to the inaccuracy of empirical observations and estimations [12]. Thus, it is of indispensability to exploit more robust optimization techiques for planning WEN corresponding to the associated complexities and uncertainties [13].

Recently, lots of efforts were made in WEN for dealing with uncertainties such as integrated energy system modelling (IESM), multi-objective programming (MOP), two-level programming (TLP), system dynamics approach (SDA). For example, Zhang and Vesselinov [14] proposed a bi-level model for handling the tradeoffs in WEN problems. Bieber et al. [15] developed an integrated modelling for the WEF nexus system, where ABM was used for simulating varied resource demands and scenario-based approaches were used for presenting different policies. Li et al. [16] used an incorporated multi-objective programming method to planning the agricultural WEF, where contradictions among water, energy, food and land are handled. Feng et al. [17] used the system dynamics approach for modeling the nexus across water, power and environment in Hehuang Region, China. In general, the above studies mainly focused on handling WEN tradeoffs through using the modeled scenarios among different policies or varied views of decision makers, and overall satisfaction of the two-level decision makers [18]. However, few of them are specialized in analyzing the intricate and complex interactions of the WEN system. For a real-world WEN system, it includes two subsystems (water subsystem and energy subsystem), and each contains multiple layers and components. Every component in each subsystem can result in changed influence on the other subsystem and pose joint shortage risk between water and energy [19]. Copula approach has its effectiveness in reflecting joint-violation risk through modeling multivariate joint distributions [20].

\subsection{Contribution}


This study aims to propose a copula-based fuzzy interval-random programming (CFIP) approach for multi-uncertainty reflection by combining copula-based random programming (CRP), interval-parameter programming (IPP) and fuzzy possibilistic programming (FPP). Compared to the deterministic quantitatively analysis methods in Al-Ansari et al. [8], Wang and Chen [9], Chhipi-Shrestha et al. [10] and Khan et al. [11], CFIP can handle complexities and uncertainties existing in WEN management problems. In comparison with the inexact optimization methods in Zhang and Vesselinov [14], Bieber et al. [15], Li et al. [16], and Feng et al. [17], CFIP can not only deal with uncertainties presented by the interval and fuzzy information but also tackle the random water resources availability and electricity demand as well as the correlative system joint-risk. Summarily, CFIP combines the superiority of CRP, IPP and FPP into one framework, which can efficaciously: (a) deal with the uncertainties expressed as random variables, interval values and fuzzy sets as well as their combinations (i.e. interval-fuzzy modulus and interval-random variables); (b) reveal the water-shortage risk, electricity-shortage risk as their correlated joint-shortage risk. Then, a CFIP-WEN model is developed and then applied to the WEN system of Henan Province, China. In the CFIP-WEN model, four classes of copulas (i.e. Clayton, Frank, Gumbel and Student's t copulas), five scenarios with different groups of water resources availability and electricity consumption, four $\lambda$ levels corresponding to decision makers' different necessity degrees of the system cost are considered. Results will help decision makers: (a) identify the desired electricity-supply patterns under the conflicts among economic objective, water resources shortage and electricity demand as well as environmental requirement; (b) analyze interactions between water resources availability and electricity consumption, and disclose their joint risk on WEN system associated with different scenarios.

\section{Methodology}

CRP has advantages of capturing the dependence of bivariate or multivariate random variables and binding disparate univariate marginal distributions together through constructing their joint distribution based on a copula function [21]. According to Charnes and Cooper [22], Chen et al. [23], Simic and Dabic-Ostojic [24], a generic CRP model can be depicted as

$$
\operatorname{Min} E=\sum_{j=1}^{n} c_{j} x_{j}
$$


subject to:

$$
\begin{aligned}
& \sum_{j=1}^{n} a_{i j} x_{j} \leq b_{i}^{p_{i}}, i=1,2, \ldots, k \\
& C\left(1-p_{1}, 1-p_{2}, \ldots, 1-p_{k}\right)=1-p \\
& \sum_{j=1}^{n} a_{i j} x_{j} \leq b_{i}, i=k+1, k+2, \ldots, m \\
& x_{j} \geq 0, j=1,2, \ldots, n
\end{aligned}
$$

where $x_{j}$ are decision variables; $a_{i j}$ and $b_{i}$ are coefficients; $b_{i}^{p_{i}}$ are random variables; $C$ is the determinate copula; $p_{i}(i=1,2, \ldots, k)$ are constraint-violation levels; $b_{i}^{p_{i}}=F_{i}^{-1}\left(p_{i}\right)$.

For a real-world WEN system, some economic parameters are affected by the socio-economic, political, legislation and technical factors, which can hard to be achieved as stochastic variables but can be presented as interval values through using the IPP technique [25]. Some imprecise data can rarely be achieved as randomness and interval but can be presented by fuzzy sets [26]. Through introducing IPP and FPP into CRP, a CFIP model can be formulated as:

$$
\operatorname{Min} \underset{\sim}{E^{ \pm}}=\sum_{j=1}^{n} \underset{\sim}{\underset{c}{c_{j}^{ \pm}}} x_{j}^{ \pm}
$$

subject to:

$$
\begin{aligned}
& \sum_{j=1}^{n} a_{i j}^{ \pm} x_{j}^{ \pm} \leq b_{i}^{\left(p_{i}\right) \pm}, i=1,2, \ldots, k \\
& C\left(1-p_{1}, 1-p_{2}, \ldots, 1-p_{k}\right)=1-p \\
& \sum_{j=1}^{n} a_{i j}^{ \pm} x_{j}^{ \pm} \leq b_{i}^{ \pm}, i=k+1, k+2, \ldots, m \\
& x_{j}^{ \pm} \geq 0, j=1,2, \ldots, n
\end{aligned}
$$

where $a_{i j}^{ \pm} \in\left\{R^{ \pm}\right\}^{m \times n}, b_{i}^{ \pm} \in\left\{R^{ \pm}\right\}^{m \times 1}, c_{\sim j}^{ \pm} \in\left\{R^{ \pm}\right\}^{1 \times n}, x_{j}^{ \pm} \in\left\{R^{ \pm}\right\}^{n \times 1} ; R^{ \pm}$mean interval numbers; ${\underset{\sim}{j}}_{j}^{ \pm}$ represent fuzzy-boundary intervals. Based on Inuiguchi and Ramik [27], Model (2) can be converted into: 
subject to:

$$
\begin{aligned}
& \sum_{j=1}^{l} a_{i j}^{ \pm} x_{j}^{ \pm}+\sum_{j=l+1}^{n} a_{i j}^{ \pm} x_{j}^{ \pm} \leq b_{i}^{\left(p_{i}\right) \pm}, i=1,2, \ldots, k \\
& C\left(1-p_{1}, 1-p_{2}, \ldots, 1-p_{k}\right)=1-p \\
& \sum_{j=1}^{l} a_{i j}^{ \pm} x_{j}^{ \pm}+\sum_{j=l+1}^{n} a_{i j}^{ \pm} x_{j}^{ \pm} \leq b_{i}^{ \pm}, i=k+1, k+2, \ldots, m \\
& x_{j}^{ \pm} \geq 0, j=1,2, \ldots, n
\end{aligned}
$$

where $\lambda$ means p-necessity level [28]. In this study, two-step method (TSM) is used for obtaining interval values of the CFIP model (i.e. $f_{\mathrm{opt}}^{ \pm}=\left[f_{\mathrm{opt}}^{-}, f_{\mathrm{opt}}^{+}\right]$and $x_{\mathrm{opt}}^{ \pm}=\left[x_{\mathrm{opt}}^{-}, x_{\mathrm{opt}}^{+}\right]$) under each $p$ level and each $\lambda$ level [29].

\section{Case Study}

Henan Province sits in the central China and covers an area of $167 \times 10^{3} \mathrm{~km}^{2}$. It consists of 17 prefectural-level cities and 1 city administrated by province, as shown in Figure 1. In 2017, the gross domestic product (GDP) and total population of Henan reached to RMB 4,498.82 billion and 108.53 million, respectively. Most rivers in Henan originate from mountainous areas in the west, northwest and southeast, among which 560 rivers covering an area of more than $100 \mathrm{~km}^{2}$. The annual average amounts of water resources reached 40.35 billion $\mathrm{m}^{3}$, ranking $19^{\text {th }}$ in China. However, the per capita water resources were about $383 \mathrm{~m}^{3}$, merely accounting for one-fifth of the national average. The limited water resources and increased water demand are increasingly restricting the sustainable development of Henan Province accompanied with anticipated climate change [30].

Place Figure 1 here 
As a primary agricultural province, agriculture occupies the primary role in the whole water use, followed by the industry, consumption and ecological protection sectors (Figure 2).For Henan Province, several electricity-conversion technologies such as conventional thermal plants (coal-fired power and nature gas-fired power) and renewable-energy based power plants (hydropower, wind, solar and biomass power) are mainly used for satisfying the local electricity demand. Simultaneously, the conversion processes of these facilities also need water in cooling, steam generation, desulfurization and cleaning. In this study, the modeling parameters are presented as interval values, probability distributions, fuzzy sets as well as their correlated dual uncertainties (i.e. interval-fuzzy modulus and interval-random variables). For example, the correlative water-consumption is subjected to a range of factors (i.e. electricity conversion type, cooling mode, as well as other weather conditions) [4]. The pollutant-emission coefficients and other technical parameters (i.e. residual capacity, capacity expansion, service time, energy consumption rate and power consumption rate) are associated with series of factors such as the energy resources type, energy quality, combustion condition and operation condition, as well as other weather conditions [31]. Thus the correlative water-consumption parameters, pollutant-emission coefficients and other technical parameters are expressed as intervals. Economic coefficients which are closely related to the volatility of interest rates, inflation rates and other factors (i.e., energy price, labor fee, and operation condition) are presented as interval-fuzzy modulus with known fuzzy possibility distributions [32]. Water resources availability and electricity demand which are affected by meteorologic, hydrologic and sociometric conditions are presented as interval-random variables [33].

Place Figure 2

\begin{abstract}
Based on the CFIP method, a provincial-scale CFIP-WEN model is formulated for the purpose of minimizing the system cost, which consists of cost of water resources, energy resources, electricity-generation, -import and -transmission as well as contamination controlling. For example, for a real-world WEN system planning issues, the cost of water resources for electricity generation mainly consists of the processes of cooling, boiling and desulfurization as well as others [32]. Energy import cost includes the cost of importing local and adjacent energies during
\end{abstract}




\section{Cost of water resource for electricity generation}

$$
\begin{aligned}
& \operatorname{Min} \underset{\sim}{E^{ \pm}}=\overbrace{\sum_{k=1}^{2} \sum_{t=1}^{6} E G A_{k, t}^{ \pm} \times\left(C C{\underset{\sim}{k, t}}_{k}^{ \pm} \times C W_{k, t}^{ \pm}+C B{\underset{\sim}{W}, t}^{ \pm} \times B W_{k, t}^{ \pm}+C D W_{k, t}^{ \pm} \times D W_{k, t}^{ \pm}\right)+\sum_{k=3}^{6} \sum_{t=1}^{6} E G A_{k, t}^{ \pm} \times C O W_{k, t}^{ \pm} \times O W_{k, t}^{ \pm}} \\
& +\underbrace{\sum_{k=1}^{2} \sum_{t=1}^{6} P E C_{\sim, t}^{ \pm} \times E G A_{k, t}^{ \pm} \times F E_{k, t}^{ \pm}+\sum_{t=1}^{6} P E J_{\sim}^{ \pm} \times P E_{t}^{ \pm}}+\underbrace{\sum_{k=1}^{6} \sum_{t=1}^{6} E G A_{k, t}^{ \pm} \times C U_{\sim k, t}^{ \pm}} \\
& \text {Cost for importing energy resources and electricity Cost for electricity transmission } \\
& +\underbrace{\sum_{k=1}^{6} \sum_{t=1}^{6}\left(E G A_{k, t}^{ \pm} \times V G C_{\sim, t}^{ \pm}\right)+\sum_{k=1}^{6} F G C_{\sim, t}^{ \pm} \times\left(R C_{k, t=0}^{ \pm}+\sum_{t=1}^{6} E C_{k, t}^{ \pm}\right)}_{\text {Cost for electricity generation }}+\underbrace{\sum_{k=1}^{6} \sum_{t=1}^{6}\left(F E C_{\sim, t}^{ \pm} \times Y C_{k, t}^{ \pm}+V E C_{\sim, t}^{ \pm} \times E C_{k, t}^{ \pm}\right)}_{\text {Cost for capacity expansion }} \\
& +\underbrace{\sum_{k=1}^{6} \sum_{t=1}^{6} \sum_{q=1}^{3} E G A_{k, t}^{ \pm} \times\left(3.6 \times C{\underset{\sim t, q}{ \pm}}_{ \pm}^{ \pm}+C{\underset{\sim}{t, q}}_{ \pm}^{ \pm} / S T_{k, t}^{ \pm}-3.6 \times S U_{\sim}^{ \pm}\right)}_{\text {Cost for pollutant reduction }}+\underbrace{\sum_{k=1}^{\sum_{t=1}^{6}} E G A_{k, t}^{ \pm} \times \delta_{\sim, t}^{ \pm} \times \mu_{k, t}^{ \pm}}_{\text {Cost for } \mathrm{CO}_{2} \text { mitigation }}
\end{aligned}
$$

The constraints are:

(1) System joint-risk constraint between water resources availability and electricity demand, which is used for guaranteeing that each individual chance constraint should be satisfied the acceptable joint-risk of constraint violation.

$$
C\left(1-p_{1}, 1-p_{2}\right)=1-p
$$

(2) Water resource availability constraint, which is established to ensure that the amount of water consumption must be not less than the total available water resources amounts.

$$
\operatorname{Pr}\left\{\sum_{k=1}^{2} E G A_{k, t}^{ \pm} \times\left(C W_{k, t}^{ \pm}+B W_{k, t}^{ \pm}+D W_{k, t}^{ \pm}\right)+\sum_{k=3}^{6} E G A_{k, t}^{ \pm} \times O W_{k, t}^{ \pm} \leq T A W_{t}^{ \pm}\right\} \geq 1-p_{1}
$$

(3) Constraint for water demand-supply, which is formulated to ensure that the total water 
consumption (i.e. cooling water, boiler water, desulfurization water and other water) should not be less than the amount of water resources demands.

$$
\sum_{k=1}^{2} E G A_{k, t}^{ \pm} \times\left(C W_{k, t}^{ \pm}+B W_{k, t}^{ \pm}+D W_{k, t}^{ \pm}\right)+\sum_{k=3}^{6} E G A_{k, t}^{ \pm} \times O W_{k, t}^{ \pm} \geq W D B_{t}^{ \pm}
$$

(4) Energy resource availability constraint: This constraint is established to ensure that the amount of energy utilization must be not less than the total available energy amounts.

$$
E G A_{k, t}^{ \pm} \times F E_{k, t}^{ \pm} \leq A R_{k, t}^{ \pm}
$$

(5) Capacity limitation constraints: These constraints are established to ensure that the capacity will satisfy the demand of electricity from a long-term planning point of view. The related optimization analysis will require the use of integer variables to indicate whether a particular facility development or expansion option needs to be undertaken.

$$
\begin{aligned}
& E G A_{k, t}^{ \pm} \leq\left(R C_{k, t=0}^{ \pm}+\sum_{t^{\prime}=0}^{t-1} E C_{k, t}^{ \pm}\right) \times S T_{k, t}^{ \pm} \\
& Y C_{k, t}^{ \pm}\left\{\begin{array}{l}
=1 ; \quad \text { if capacity expasion is undertaken } \\
=0 ; \quad \text { if otherwise }
\end{array}\right\} \\
& 0 \leq E C_{k, t}^{ \pm} \leq M C_{k, t}^{ \pm} \times Y C_{k, t}^{ \pm}
\end{aligned}
$$

(6) Constraint for electricity demand-supply: These constraints are established to ensure that the total electricity generated from the existing and future expanding capacities, and purchased from other power grids should not be less than the amount of electricity demands.

$$
\operatorname{Pr}\left\{\left(\sum_{k=1}^{6} E G A_{k, t}^{ \pm} \times\left(1-Z L_{k, t}^{ \pm}\right) \times T E_{k, t}^{ \pm}+P E_{t}^{ \pm}\right) \times\left(1-\eta_{t}^{ \pm}\right) \geq E D B_{t}^{ \pm}\right\} \geq 1-p_{2}
$$

(7) Constraint for pollutant and $\mathrm{CO}_{2}$ emissions: These constraints are used for ensuring that the pollutant-emission amounts should be satisfied by the pollutant-emission permits.

$$
\begin{aligned}
& \sum_{k=1}^{6} E G A_{k, t}^{ \pm} \times A M R_{k, t, q}^{ \pm} \leq E S_{t, q}^{ \pm} \\
& \sum_{k=1}^{6} E G A_{k, t}^{ \pm} \times \delta_{k, t}^{ \pm} \times\left(1-C C A_{t}^{ \pm}\right) \leq E S C_{t}^{ \pm}
\end{aligned}
$$

(8) Nonnegative constraints: This constraint assures that only positive electricity-conversion activities are considered in the solution, eliminating infeasibilities while calculating the solution.

$$
E G A_{k, t}^{ \pm}, P E_{t}^{ \pm}, E C_{k, t}^{ \pm} \geq 0
$$


The abbreviation and detailed explanations of system coefficients are given in Appendix. The system coefficients from sociometric, technical, subjective and observed or estimated aspects were collected from the Statistical Yearbook of Henan Province, survey questionnaires and expert consultations, as well as the Henan Provincial Water Resources Bulletin [36-38]. Besides, four classes of copulas such as Clayton, Frank, Gumbel and Student's t copulas were used to model the joint distribution of water resource availability and electricity consumption. The joint cumulative distribution functions for water resources availability and electricity consumption under four copulas were shown in Figure 3. The RMSE, MSE, AIC and BIC values for joint cumulative distributions of these selected copulas were shown in Table 1. Results indicate that Frank copula was superior to other copulas in connecting the marginal distributions of water resource availability and electricity consumption. The selected scenarios for joint and individual constraint-violation levels $\left(p, p_{1}, p_{2}\right)$, being $(0.1,0.02,0.2),(0.1,0.1,0.3188)$, $(0.1,0.1063,0.1063),(0.1,0.15,0.1001)$ and $(0.1,0.02,0.2)$ from scenario 1 to scenario 5 (abbreviated as S1, S2, S3, S4 and S5), as detailed in [39].

Place Figure 3, Table 1 here

\section{Result Analysis}

Figure 4 presents the electricity-supply schemes under different scenarios. Summarily, the percentage of electricity by coal-fired power would change with the variation of scenarios, which range from $[79.2,80.8] \%(\mathrm{~S} 1)$ to $[81.8,82.6] \%(\mathrm{~S} 5)$. This is because low water-resources availability would force the managers to select more renewable energy-based electricity owing to the consideration of system reliability, economic development and water consumption; conversely, managers would tend to choose more local fossil energy-based electricity under high water-resources availability. Besides, since the renewable energy-based electricity is subject to the capacity limitation of renewable energy resources, the variation of associated electricity-generation would change very little. Figure 5 presents the electricity-generation pattern for each power plant in each year. Generally, the local electricity supply is primarily 
depending on the coal-fired power even having a decreasing trend from [84.1, 85.5] \% to [74.9, 76.5] \% during the planning horizon. Gas-fired power and hydropower would take minor shares for the WEN system while having an increasing tendency. The remaining power plants such as wind power, solar power and biomass power would occupy small contributions for the local electricity-supply because of the limited energy resources, small capacities, and high investment costs.

Place Figures 4 and 5 here

Figure 6 shows the expanded capacities of power conversion facilities in each year. Summarily, the expanded capacity of each power conversion facility in each year would be different. Coal-fired power would have no expansion scheme while wind power and solar power would have high expansion scheme over the planning horizon. For example, the lower bound of expanded capacity for wind power would be $0.68 \mathrm{GW}$ in year 1, $0.68 \mathrm{GW}$ in year 2, $0.69 \mathrm{GW}$ in year 3, $0.60 \mathrm{GW}$ in year $4,0.59 \mathrm{GW}$ in year 5 and $0.59 \mathrm{GW}$ in year 6 , respectively. This is mainly because decision makers would incline to choose more local electricity-generation having low water-consumption and pollutant-discharge. Moreover, energy management decision makers would prefer to developing local renewable energies in order to improve the local power security and promote urban sustainable development in the long run. Figure 7 depicts the imported electricity under different scenarios. Results disclose that the imported electricity would decrease with time, and the imported electricity would decrease from $[176.37,192.66] \times 10^{3} \mathrm{GWh}$ in year 1 to $[175.21,159.70] \times 10^{3} \mathrm{GWh}$ in year 6 under S1. Results also demonstrate that different scenarios would contribute to varied amounts of imported electricity. The variation of imported electricity would change around $16.3 \%$ between S1 and S2 at the end planning horizon.

Place Figures 6 and 7 here

Figure 8 presents the water consumption for each power plant under different scenarios. Generally, interactions of water availability and electricity demand would change the total water 
consumption, and the total water consumption would approximately increase by [194.9, 203.4] $\times 10^{6} \mathrm{~m}^{3}$ from $\mathrm{S} 1$ to $\mathrm{S} 5$. Results also show that coal-fired power consumes more than $90 \%$ of the water consumption, and the water consumption of coal-fired power would decrease with time owing to the water availability scenarios (e.g., the more available water resources, the higher coal-fired based electricity).Thus, it is of indispensability to exploit more renewable energies having lower water-requirement to balance contradictions of water demand-supply, electricity demand-supply and pollutant mitigation.

Place Figure 8 here

Figure 9 shows the emissions of three air-pollutants (i.e. $\mathrm{SO}_{2}, \mathrm{NO}_{\mathrm{x}}$ and $\mathrm{PM}_{10}$ ) and $\mathrm{CO}_{2}$. Results indicate that different water availability scenarios would affect the electricity-generation pattern and then lead to the variation of pollutant-emission pathway (e.g., the emissions of pollutants would have a downward trend from S5 to S1). Moreover, under S5 (i.e. the water resources availability generates none effects on the coal-fired power), the average amount of $\mathrm{CO}_{2}$ would decrease from $21.63 \times 10^{6}$ tonne (year 1 ) to $21.30 \times 10^{6}$ tonne (year 6). This is mainly attributed to the fact that many efforts such as strict mitigation target, policy stimulation for renewable energy and improvement of pollutant-mitigation efficiency play jointly contributions for reducing pollutants and $\mathrm{CO}_{2}$ emissions. Thus, some new technologies (e.g., wind power and solar power) that can both meet electricity-demand and reduce pollutant emissions should be further adopted.

Place Figure 9 here

Uncertainties existed in modeling parameters would lead to varied system costs. As shown in Figure 10 , when $\lambda=1$, system cost would increase by $\$[0.18,0.19] \times 10^{12}$ under $\mathrm{S} 1$ compared to that under S2, while $[194.9,203.4] \times 10^{6} \mathrm{~m}^{3}$ of water were saved. It is mainly because a high water-resources availability violation-risk equivalent to an increased coal-fired power generation reliability, leading to a low system cost; while renewable-energy based and extra electricity from 
other power grids become of indispensability in response to a low water-resources availability violation-risk, thus resulting in a high system cost. Moreover, different $\lambda$ levels correspond to decision makers' different necessity degrees of the system cost, thus leading to changed system costs. For instance, the system cost would vary from $\$[2.99,3.39] \times 10^{12}(\lambda=1)$ to $\$[3.02,3.42]$ $\times 10^{12}(\lambda=0.65)$ under S1. Thus, there exists a trade-off among system cost, risk-averse attitude of decision-maker and water resources availability.

Place Figure 10 here

\section{Conclusions}

In this study, a CFIP method has been exploited through integration of CRP, IPP and FPP. CFIP can both handle random, interval and interval information and reflect system joint-risk employed to the WEN system of Henan Province, China. Solutions of various copulas associated with different scenarios and necessity degrees are examined in the CFIP-WEN model. CFIP-WEN model has advantages of: (a) disclosing interactions between water resources availability and electricity consumption, and further illustrating their interactive effects on WEN system in association with various scenarios and multiple uncertainties; (b) balancing the conflict among economic objective, water resources shortage and electricity demand, as well as environmental requirement.

Solutions for system cost, electricity-supply pattern, water-allocation pattern, and pollutant-emission associated with various scenarios and multiple uncertainties have been achieved. Results indicate that uncertainties and scenarios employed to water resources, electricity demand and other module parameters can generate prominent impacts on the WEN system. Water resources can restrict the local electricity-generation pattern and then lead to the change of system cost, and the system cost would increase by $\$[0.18,0.19] \times 10^{12}$ under S1 compared to that under $\mathrm{S} 2$, while around $[194.9,203.4] \times 10^{6} \mathrm{~m}^{3}$ of water to be saved. Compared to high water-availability scenario (S5), the share of electricity generated by the coal-fired power can decrease by $[1.8,2.6] \%$ under low water-availability scenario (S1). 


\begin{abstract}
Although CFIP-WEN model has its effectiveness in reflecting the interactions between water resources availability and electricity demand, and providing optimal solutions for WEN management, it neglects the hierarchically conflicting objectives in the WEN system (e.g., the objectives of minimum system cost and minimum water consumption), making the results incapable of presenting the real-world WEN planning issues [40]. Besides, the constraints of the CFIP-WEN model are limited to production-demand relationships, efficiency, storage and operation levels of the electricity-conversion technologies should be further considered in order to improve the robustness of the CFIP-WEN model [41]. In addition, energy- and water-supply security especially for the water-stressed area is an international challenge, some more advanced theory and robust model should be referenced to cope with such increasing energy demand and water shortage [42].
\end{abstract}

\title{
Acknowledgements
}

This research was supported by the National Natural Science Foundation of China (51909239), the Key Research Project of Henan Higher Education Institution (20A570001) and the Postdoctoral Foundation of Henan Province (1901008). The authors are grateful to the editors and the anonymous reviewers for their insightful comments and suggestions. 


\section{References}

[1] Khalkhali M, Westphal K, Mo WW. The water-energy nexus at water supply and its implications on the integrated water and energy management. Science of The Total Environment 2018;636:1257-1267.

[2] Gjorgiev B, Sansavini G. Water-energy nexus: Impact on electrical energy conversion and mitigation by smart water resources management. Energy Conversion and Management 2017;148:1114-1126.

[3] Fan JL, Kong LS, Wang H, Zhang X. A water-energy nexus review from the perspective of urban metabolism. Ecological Modelling 2019;392:128-136.

[4] Lv J, Li YP, Shan BG, Jin SW, Suo C. Planning energy-water nexus system under multiple uncertainties - A case study of Hebei province. Applied Energy 2018;229:389-403.

[5] Li N, Chen WY. Energy-water nexus in China's energy bases: From the Paris agreement to the Well Below 2 Degrees target. Energy 2019;166:277-286.

[6] Qin Y, Curmi E, Kopec GM, Allwood JM, Richards KS. China’s energy-water nexus assessment of the energy sector's compliance with the "3 Red Lines" industrial water policy. Energy Policy 2015;82:131-143.

[7] Cai YP, Cai JY, Xu LY, Tan Q, Xu Q. Integrated risk analysis of water-energy nexus systems based on systems dynamics, orthogonal design and copula analysis. Renewable and Sustainable Energy Reviews 2019;99:125-137.

[8] Al-Ansari T, Korre A, Nie ZG, Shah N. Development of a life cycle assessment tool for the assessment of food production systems within the energy, water and food nexus. Sustainable Production and Consumption 2015;2:52-66.

[9] Wang SG, Chen B. Energy-water nexus of urban agglomeration based on multiregional input-output tables and ecological network analysis: A case study of the Beijing-Tianjin-Hebei region. Applied Energy 2016;178:773-783.

[10] Chhipi-Shrestha G, Hewage K, Sadiq R. Water-energy-carbon nexus modeling for urban water systems: system dynamics approach. Journal of Water Resources Planning and Management 2017;143:04017016.

[11] Khan HF, Yang YCE, Xie H, Ringler C. A coupled modeling framework for sustainable watershed management in transboundary river basins. Hydrology and Earth System Sciences 
2017;21:6275-6288.

[12] Yu L, Li YP, Huang GH. A fuzzy-stochastic simulation-optimization model for planning electric power systems with considering peak-electricity demand: A case study of Qingdao, China. Energy 2016;98:190-203.

[13] Cai XM, Wallington K, Shafiee-Jood M, Marston L. Understanding and managing the food-energy-water nexus - opportunities for water resources research. Advances in Water Resources 2018;111:259-273.

[14] Zhang XD, Vesselinov VV. Energy-water nexus: Balancing the tradeoffs between two-level decision makers. Applied Energy 2016;183:77-87.

[15] Bieber N, Ker JH, Wang XN, Triantafyllidis C, van Dam KH, Koppelaar RHEM, Shah N. Sustainable planning of the energy-water-food nexus using decision making tools. Energy Policy 2018;113:584-607.

[16] Li M, Fu Q, Singh VP, Liu D. An interval multi-objective programming model for irrigation water allocation under uncertainty. Agricultural Water Management 2018;196:24-36.

[17] Feng MY, Liu P, Li ZJ, Zhang JW, Liu DD, Xiong LH. Modeling the nexus across water supply, power generation and environment systems using the system dynamics approach: Hehuang Region, China. Journal of Hydrology 2016;543, Part B:344-359.

[18] Pahl-Wostl C. Governance of the water-energy-food security nexus: A multi-level coordination challenge. Environmental Science \& Policy 2019;92:356-367.

[19] Thiede S, Schönemann M, Kurle D, Herrmann C. Multi-level simulation in manufacturing companies: The water-energy nexus case. Journal of Cleaner Production 2016;139:1118-1127.

[20] Su JX, Furman E. Multiple risk factor dependence structures: Copulas and related properties. Insurance: Mathematics and Economics 2017;74:109-121.

[21] Nelsen RB. An introduction to copulas. New York: Springer, 1999. ISBN 0-387-98623-5.

[22] Charnes A, Cooper WW. Response to decision problems under risk and chance constrained programming: dilemmas in the transitions. Management Science 1983;29(6):750-753.

[23] Chen F, Huang GH, Fan YR, Chen JP. A copula-based fuzzy chance-constrained programming model and its application to electric power generation systems planning. Applied Energy 2017;187:291-309.

[24] Simic V, Dabic-Ostojic S. Interval-parameter chance-constrained programming model for 
uncertainty-based decision making in tire retreading industry. Journal of Cleaner Production 2017;167:1490-1498.

[25] Li YP, Nie S, Huang CZ, McBean EA, Fan YR, Huang GH. An integrated risk analysis method for planning water resource systems to support sustainable development of an arid region. Journal of Environmental Informatics. 2017;29(1):1-15.

[26] Yu L, Li YP, Huang GH. Planning municipal-scale mixed energy system for stimulating renewable energy under multiple uncertainties-The City of Qingdao in Shandong Province, China. Energy 2019;166:1120-1133.

[27] Inuiguchi M, Ramik J. Possibilistic linear programming: a brief review of fuzzy mathematical programming and a comparison stochastic programming inportfolio selection problem. Fuzzy Sets and Systems 2000;111:3-28.

[28] Zhou Y, Li YP, Huang GH, Zhou Y. A robust approach for planning electric power systems associated with environmental policy analysis. Electric Power Systems Research 2013;95:99-111.

[29] Huang GH, Baetz BW, Patry GG. A grey linear programming approach for municipal solid waste management planning under uncertainty. Civil Engineering Systems 1992;9(4):319-335.

[30] Yin YY, Tang QH, Liu XC, Zhang XJ. Water scarcity under various socio-economic pathways and its potential effects on food production in the Yellow River basin. Hydrology and Earth System Sciences 2017;21:791-804.

[31] Li YP, Huang GH. Electric-power systems planning and greenhouse-gas emission management under uncertainty. Energy Conversion and Management 2012;57:173-182.

[32] Liu J, Li YP, Huang GH, Suo C, Yin S. An interval fuzzy-stochastic chance-constrained programming based energy-water nexus model for planning electric power systems. Energies 2017;10(11):1914.

[33] Yu L, Li YP, Huang GH, Fan YR, Nie S. A copula-based flexible-stochastic programming method for planning regional energy system under multiple uncertainties: A case study of the urban agglomeration of Beijing and Tianjin. Applied Energy 2018;210:60-74.

[34] Zhu Y, Li YP, Huang GH. Planning carbon emission trading for Beijing's electric power systems under dual uncertainties. Renewable and Sustainable Energy Reviews 2013;23:113-128. 
[35] Jin SW, Li YP, Xu LP. Development of an integrated model for energy systems planning and carbon dioxide mitigation under uncertainty - Tradeoffs between two-level decision makers. Environmental Research 2018;164:367-378.

[36] The $13^{\text {th }}$ Five-year Energy Development Plan of Henan Province. The People's Government of Henan Province; 2017. Available at: < https://www.henan.gov.cn/2017/05-24/270780.html >.

[37] Henan Provincial Water Resources Bulletin. Henan Provincial Department of Water Resources; 2017. Available at: < http://www.hnsl.gov.cn/gallery/8aa98d9267305a9a0167e45e76825bf5.html >.

[38] Henan Statistical Yearbook. Henan Provincial Bureau of Statistics; 2018. Available at: < http://www.ha.stats.gov.cn/hntj/lib/tjnj/2018/indexch.htm >.

[39] Yu L, Li QW, Jin SW, Chen C, Li YP, Fan YR, Zuo QT. A two-level based copula interval-stochastic programming approach for planning energy-water nexus system management under uncertainty. Journal of Hydrology HYDROL32062R1.

[40] Chen YZ, He L, Li J, Cheng X, Lu HW. An inexact bi-level simulation-optimization model for conjunctive regional renewable energy planning and air pollution control for electric power generation systems. Applied Energy 2016;183:969-983.

[41] Kuang JY, Zhang CH, Sun B. Stochastic dynamic solution for off-design operation optimization of combined cooling, heating, and power systems with energy storage. Applied Thermal Engineering 2019, accept. Available at < https://doi.org/10.1016/j.applthermaleng.2019.114356 >.

[42] Zhang C, Chen XX, Li Y, Ding W, Fu GT. Water-energy-food nexus: Concepts, questions and methodologies. Journal of Cleaner Production 2018;195:625-639. 


\section{List of Table Captions}

Table 1. Comparison of RMSE, MSE, AIC and BIC values for joint distributions using different

\section{copulas}




\section{List of Figure Captions}

Figure 1. The study area

Figure 2. Total water resources and -use under different sectors $\left(10^{9} \mathrm{~m}^{3}\right)$

Figure 3. Joint cumulative distribution functions for water resource availability and electricity consumption under different copulas [symbols " $\mathrm{u} 1, \mathrm{u} 2$ and $\mathrm{C}(\mathrm{u} 1, \mathrm{u} 2)$ " denote "water resource $\left(10^{8} \mathrm{~m}^{3}\right)$, electricity consumption $\left(10^{3} \mathrm{GWh}\right)$ and joint cumulative distribution function", respectively]

Figure 4. Electricity-supply scheme in the planning horizon (\%)

Figure 5. Electricity-supply scheme in each period (\%)

Figure 6. Expanded capacities of power conversion facilities (GW)

Figure 7. Imported electricity under different scenarios $\left(10^{3} \mathrm{GWh}\right)$

Figure 8. Water consumption $\left(10^{6} \mathrm{~m}^{3}\right)$

Figure 9. Pollutant and $\mathrm{CO}_{2}$ emissions

Figure 10. System costs $\left(\$ 10^{12}\right)$ 
Table 1. Comparison of RMSE, MSE, AIC and BIC values for joint distributions using different copulas

\begin{tabular}{lllll}
\multicolumn{1}{c}{ copulas } & & & & \\
\hline Copula family & RMSE & MSE & AIC & BIC \\
\hline Clayton & 0.1517 & 0.0230 & -43.2646 & -42.7797 \\
Frank & 0.0567 & 0.0032 & -66.8662 & -66.3813 \\
Gumbel & 0.1517 & 0.0230 & -43.2646 & -42.7797 \\
Student's t & 0.0624 & 0.0039 & -62.5922 & -61.6224 \\
\hline
\end{tabular}

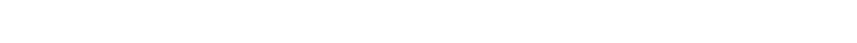




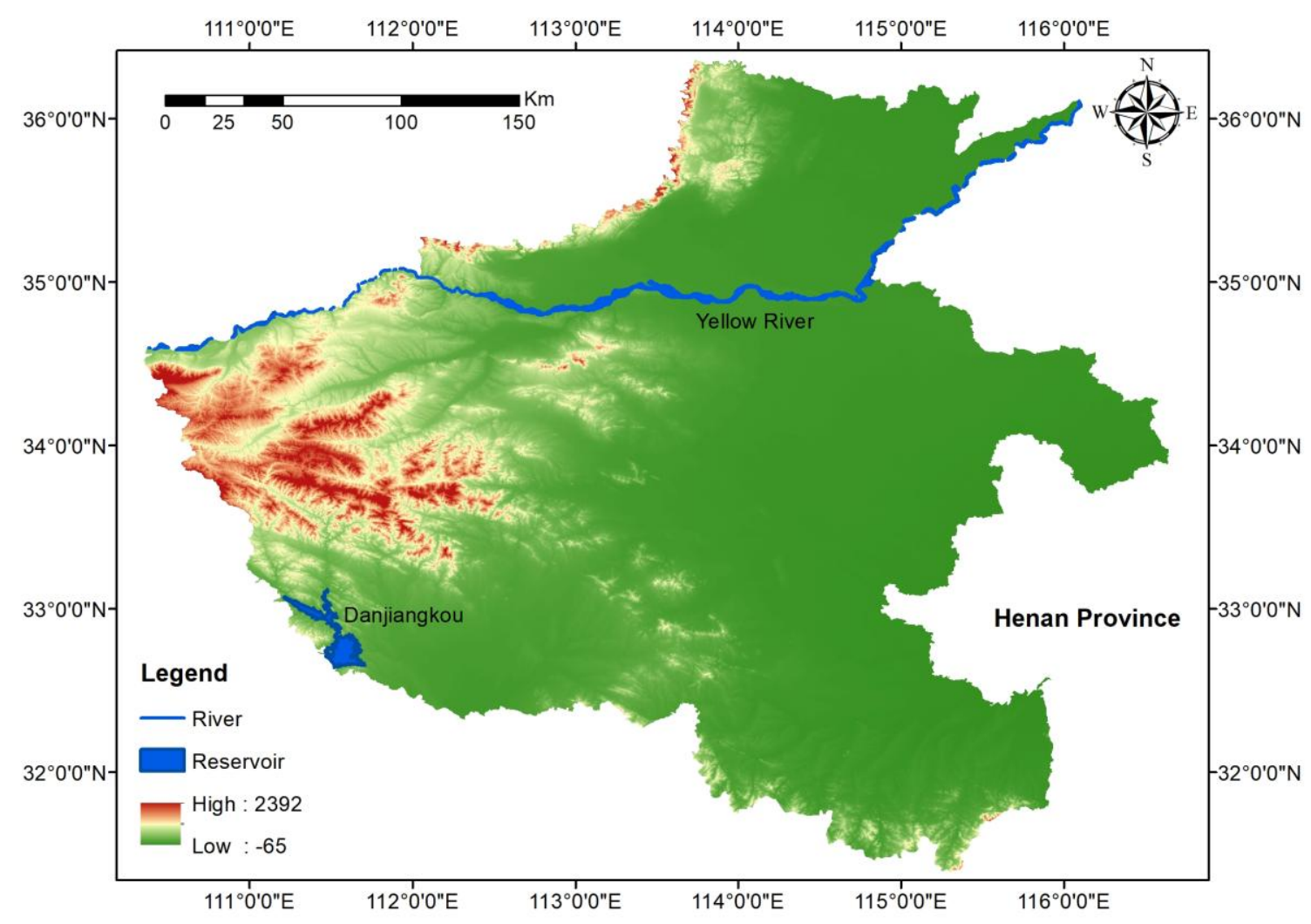

Figure 1. The study area 


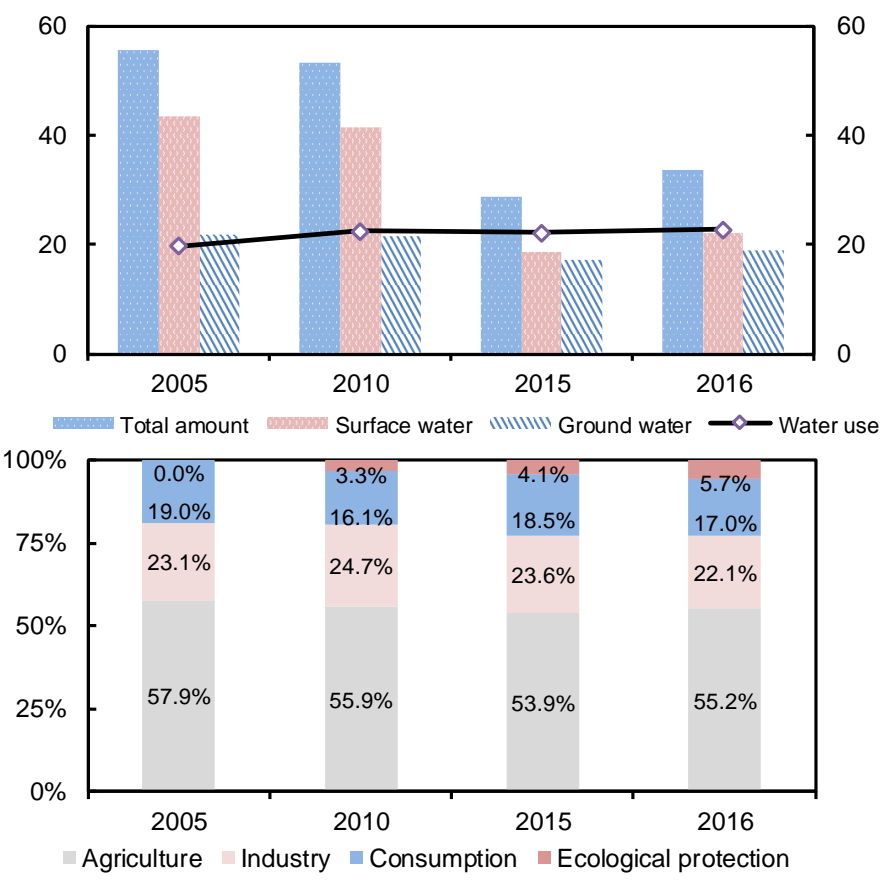

Figure 2. Total water resources and -use under different sectors $\left(10^{9} \mathrm{~m}^{3}\right)$ 

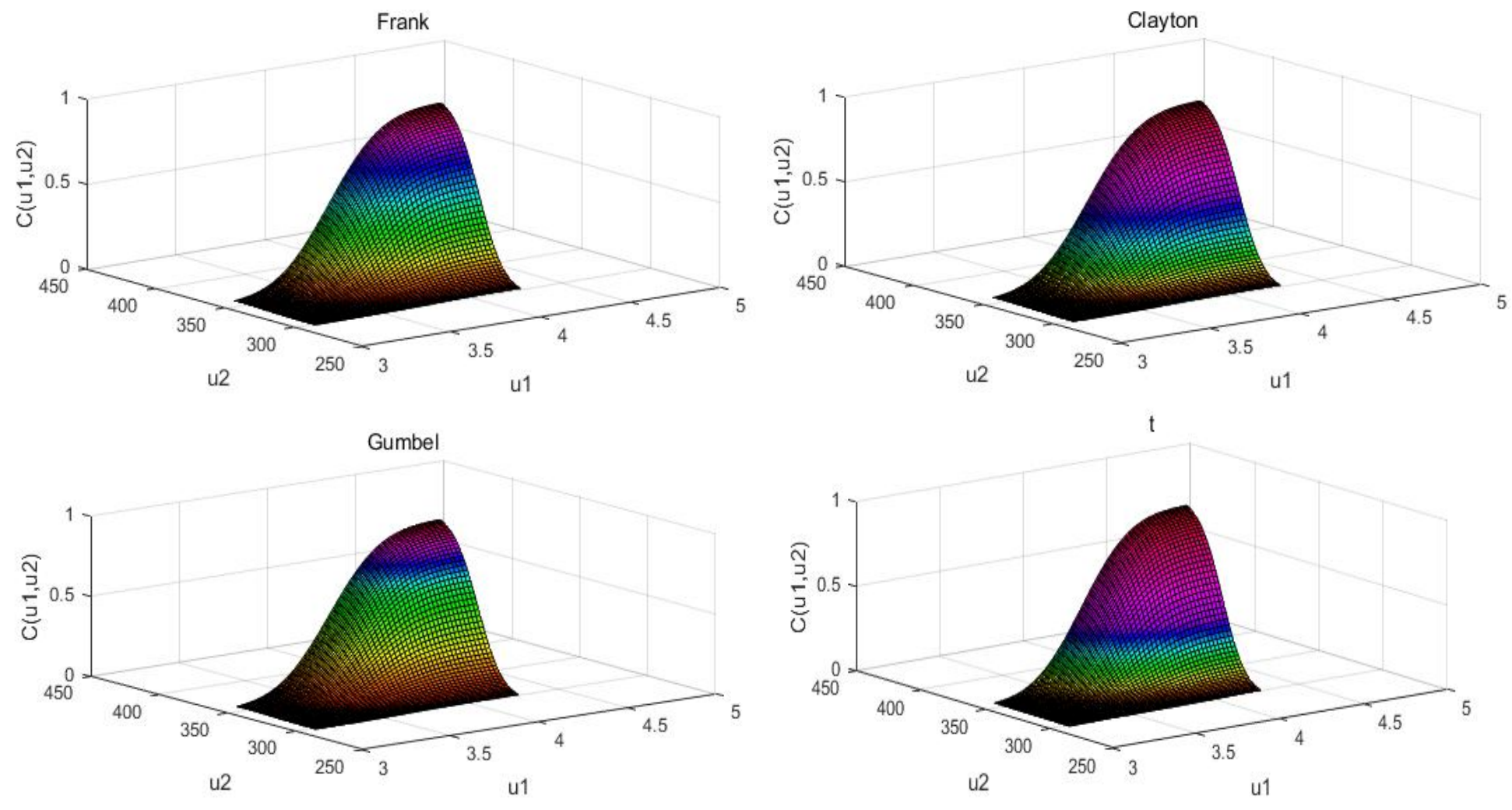

Figure 3. Joint cumulative distribution functions for water resource availability and electricity consumption under different copulas [symbols " $\mathrm{u} 1, \mathrm{u} 2$ and $\mathrm{C}(\mathrm{u} 1, \mathrm{u} 2)$ " denote "water resource $\left(10^{8} \mathrm{~m}^{3}\right)$, electricity consumption $\left(10^{3} \mathrm{GWh}\right)$ and joint cumulative distribution function", respectively] 
a) Lower bound

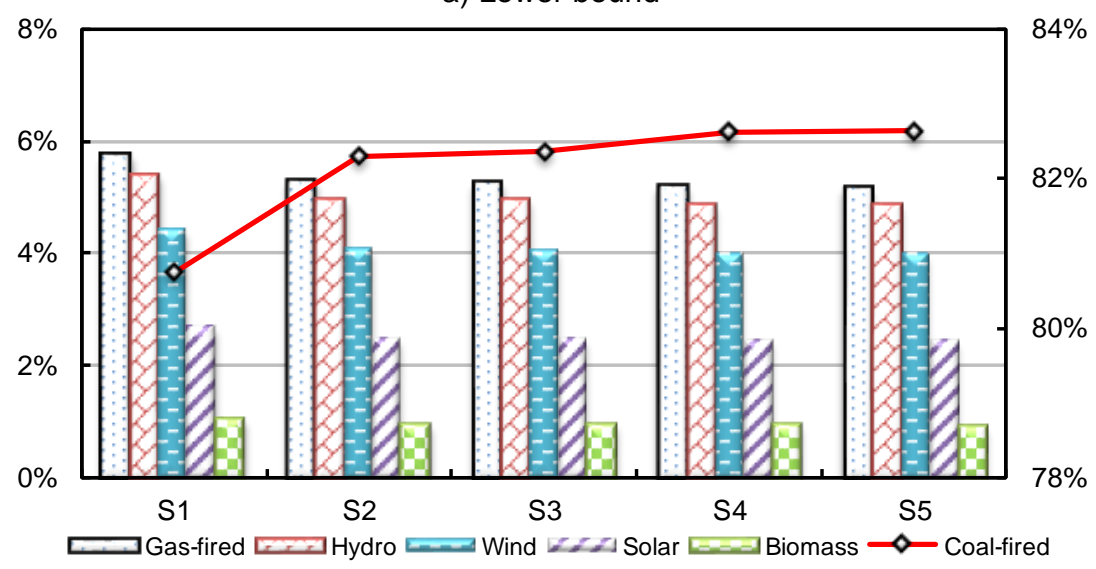

b) Upper bound

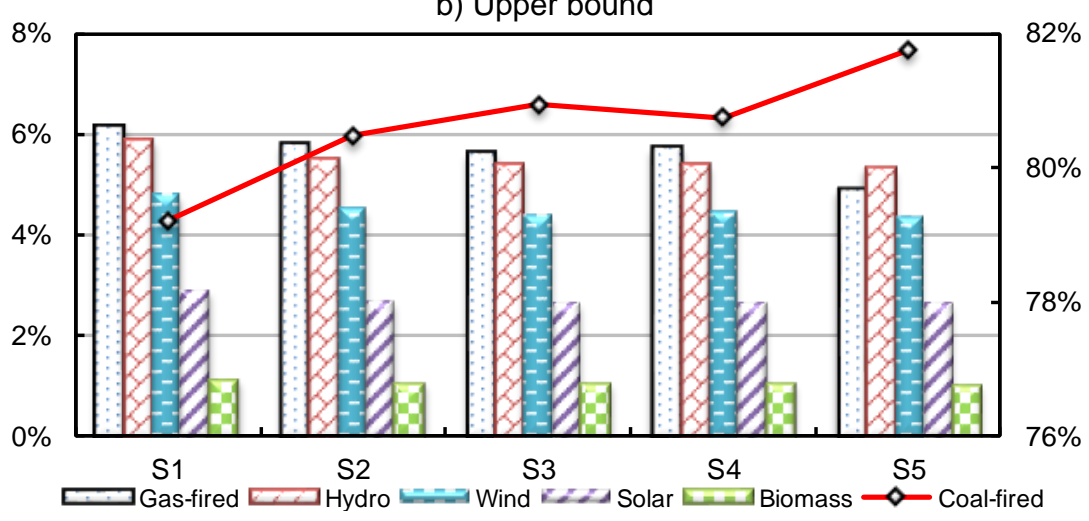

Figure 4. Electricity-supply scheme in the planning horizon (\%) 
a) Lower bound

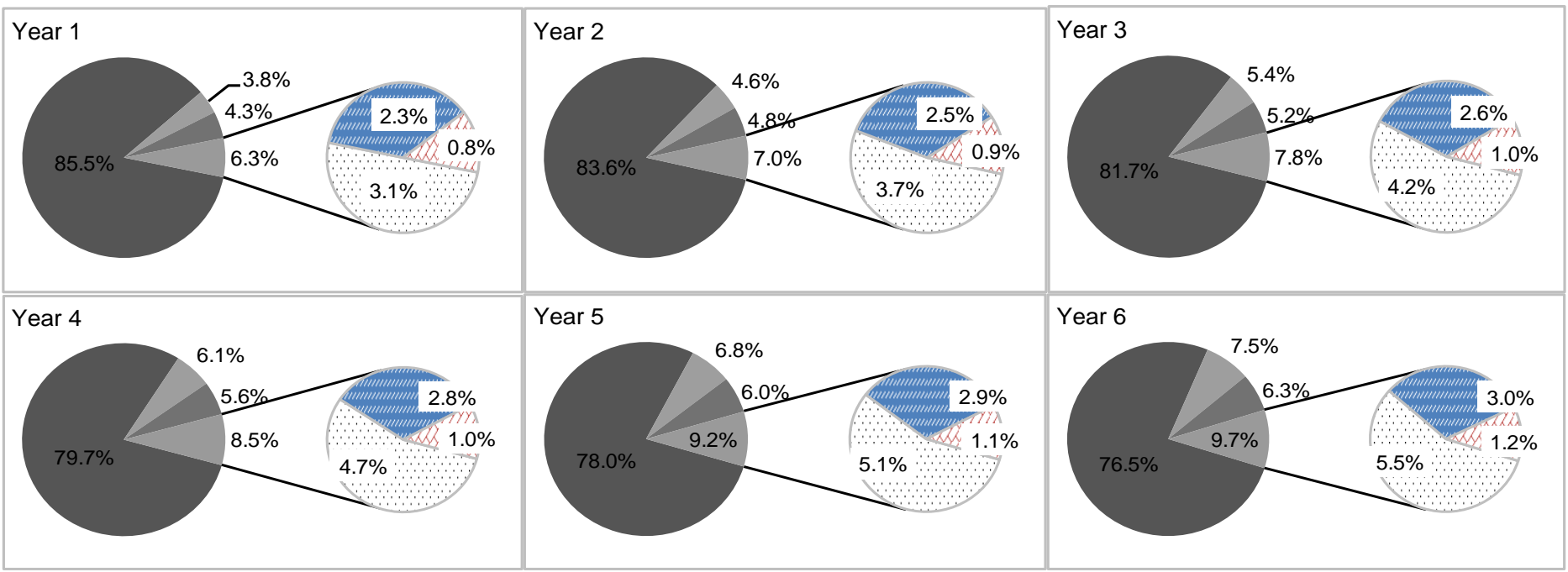

b) Upper bound
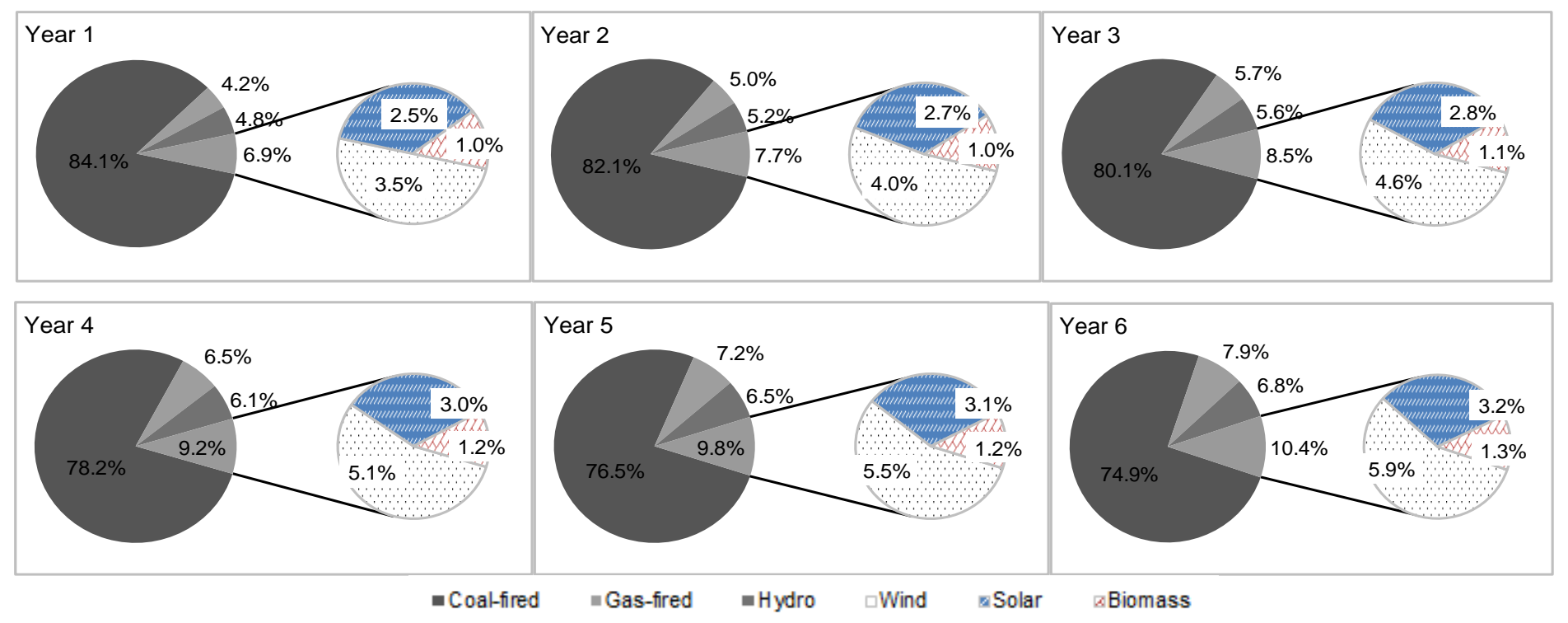

Figure 5. Electricity-supply scheme in each period (\%) 

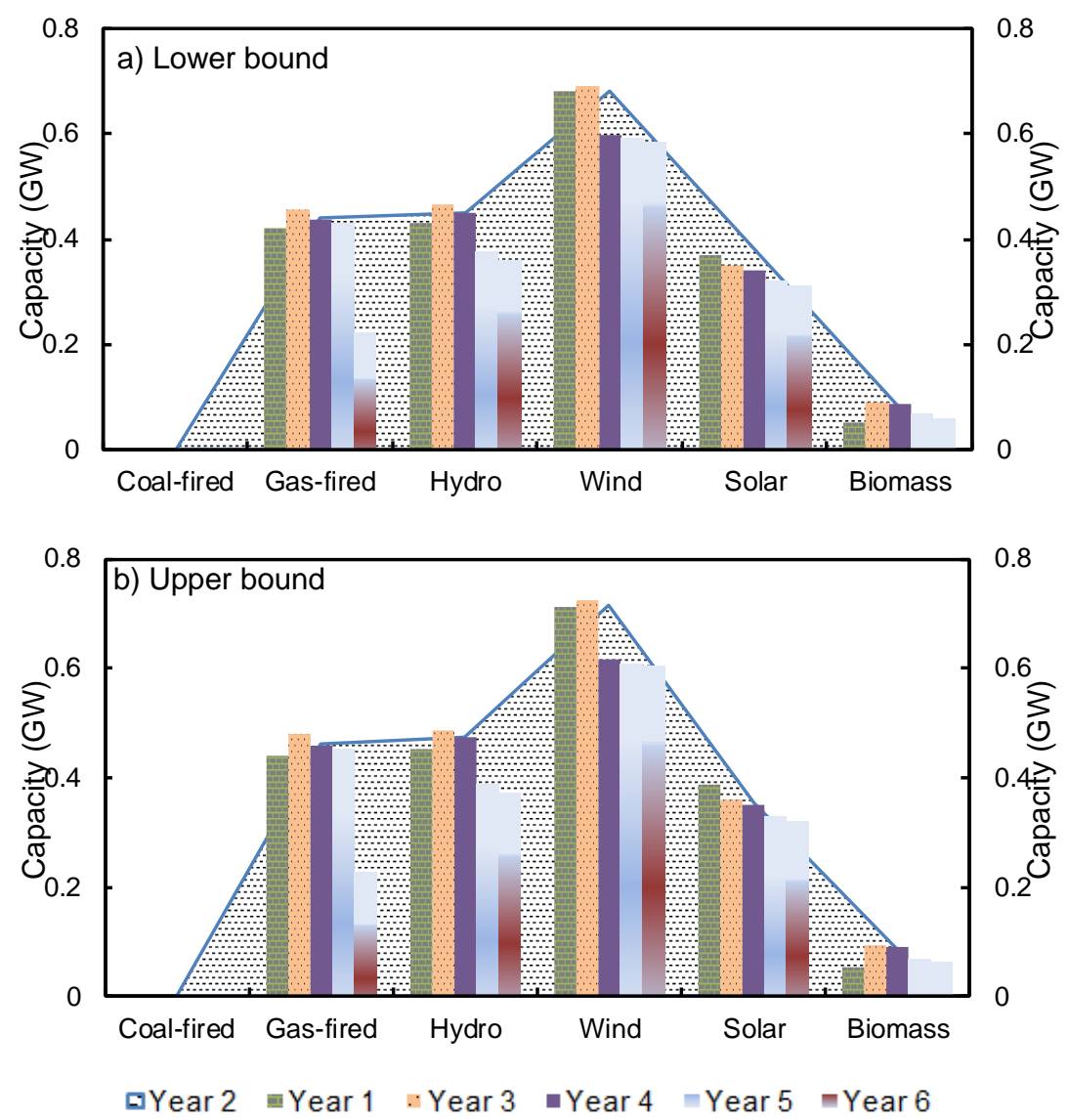

Figure 6. Expanded capacities of power conversion facilities (GW) 
a) Lower bound

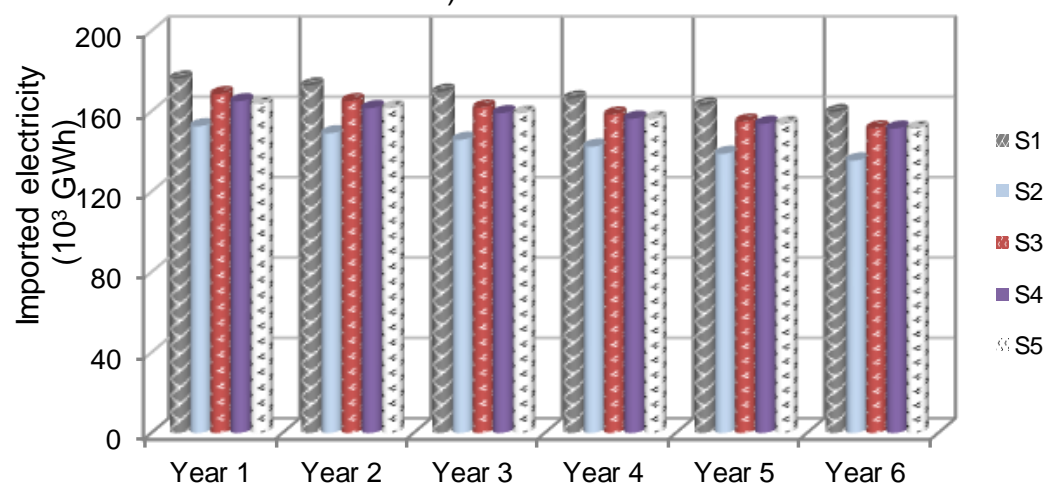

b) Upper bound

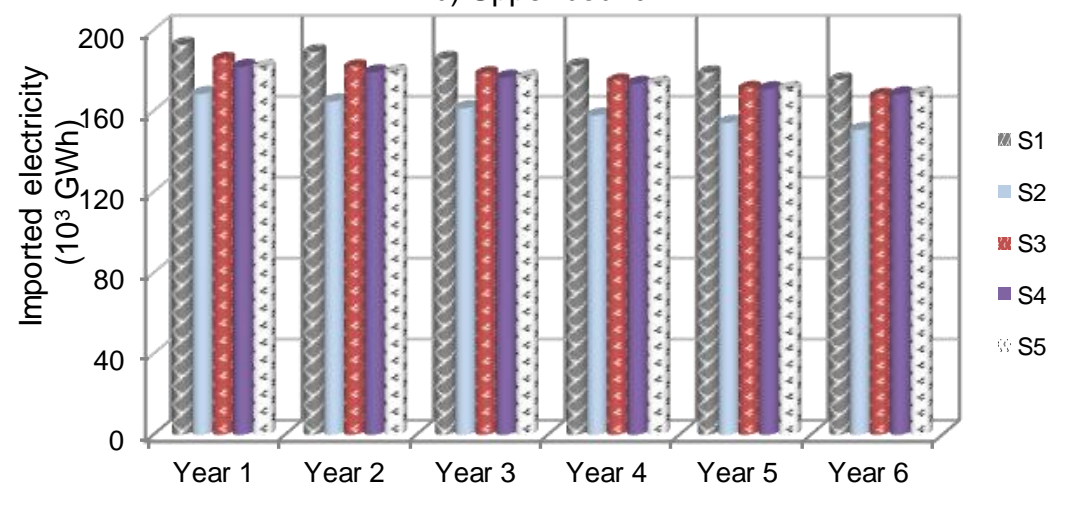

Figure 7. Imported electricity under different scenarios $\left(10^{3} \mathrm{GWh}\right)$ 

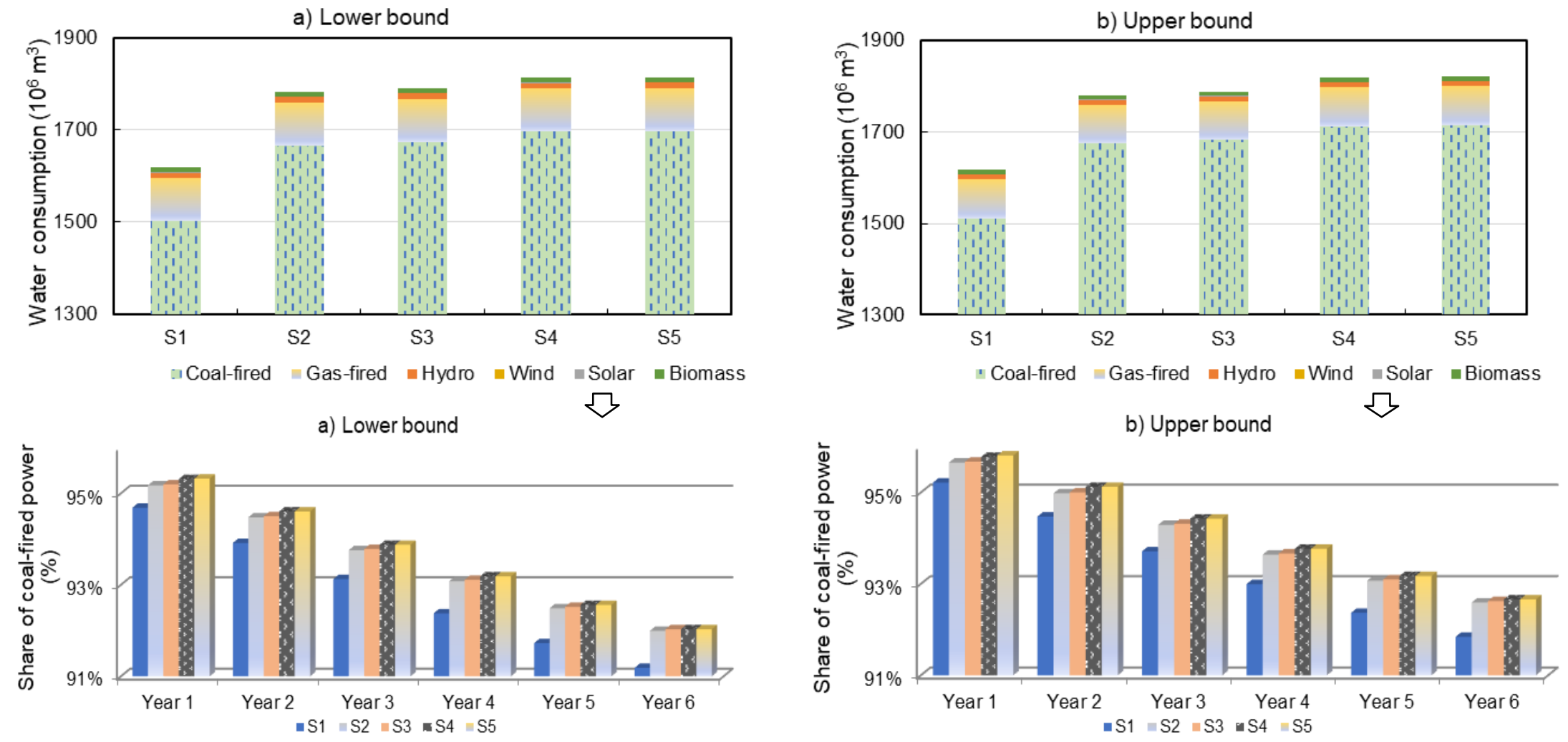

Figure 8 . Water consumption $\left(10^{6} \mathrm{~m}^{3}\right)$ 


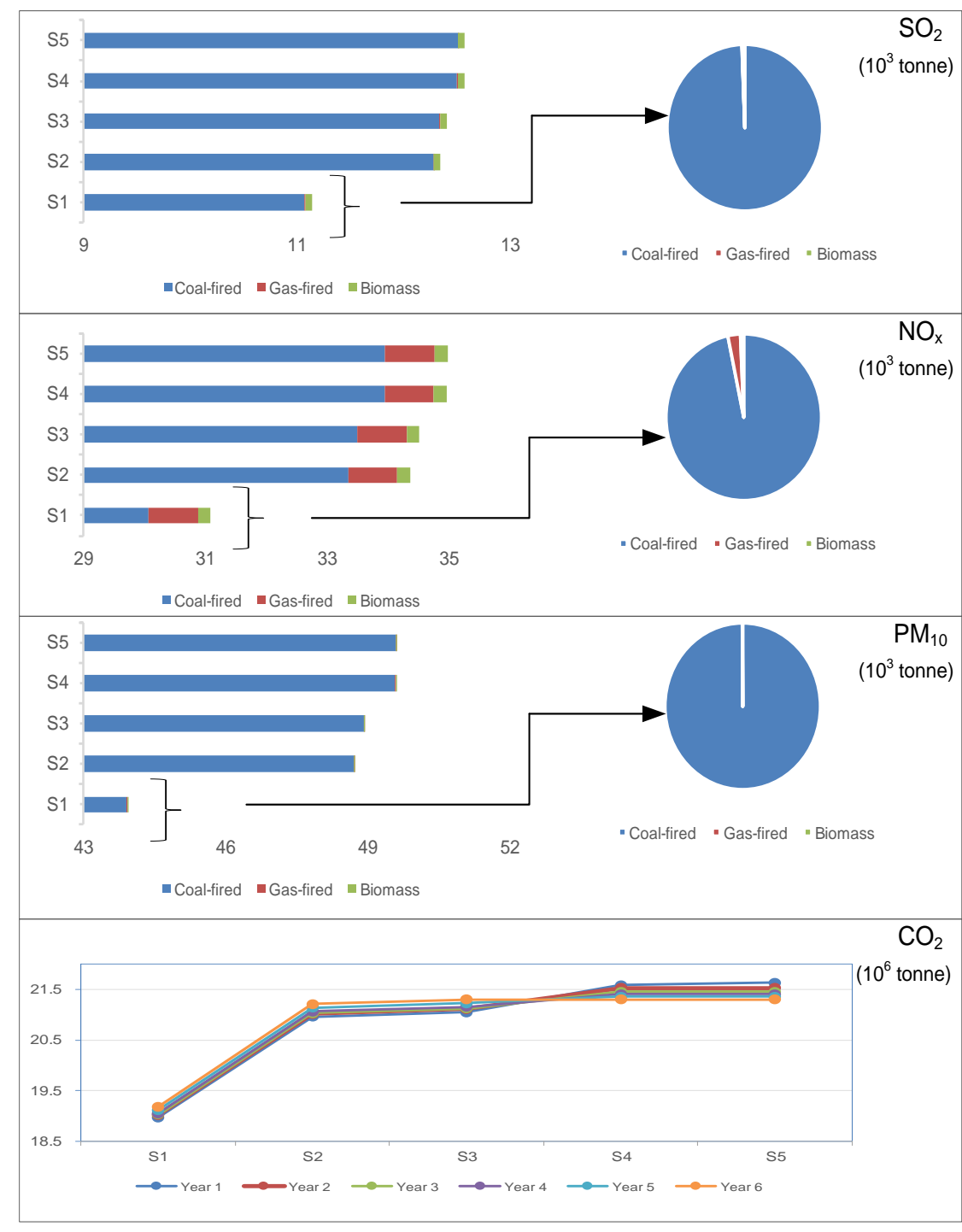

Figure 9. Pollutant and $\mathrm{CO}_{2}$ emissions 
a) Lower bound

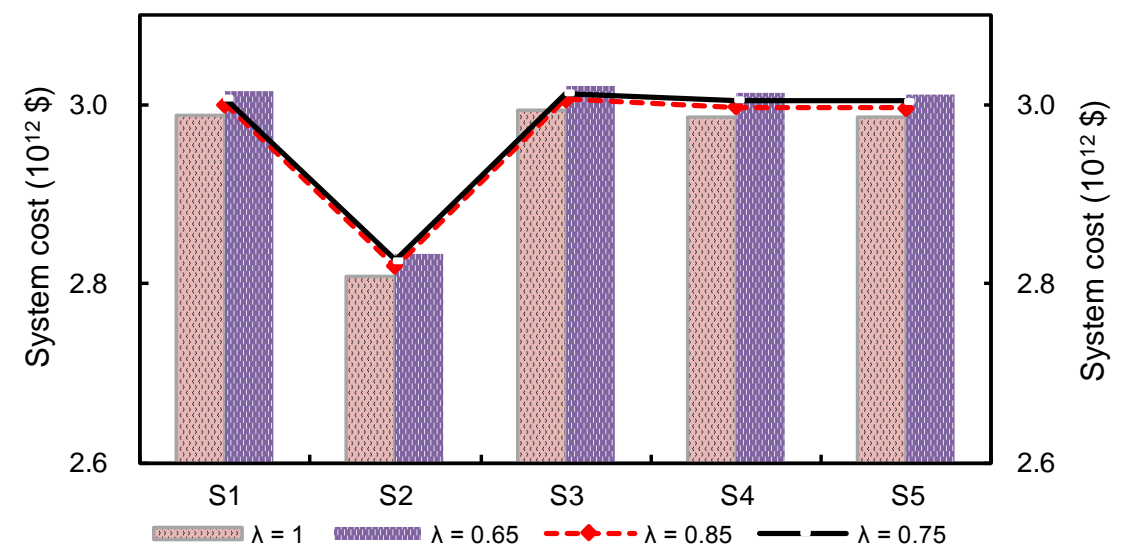

b) Upper bound

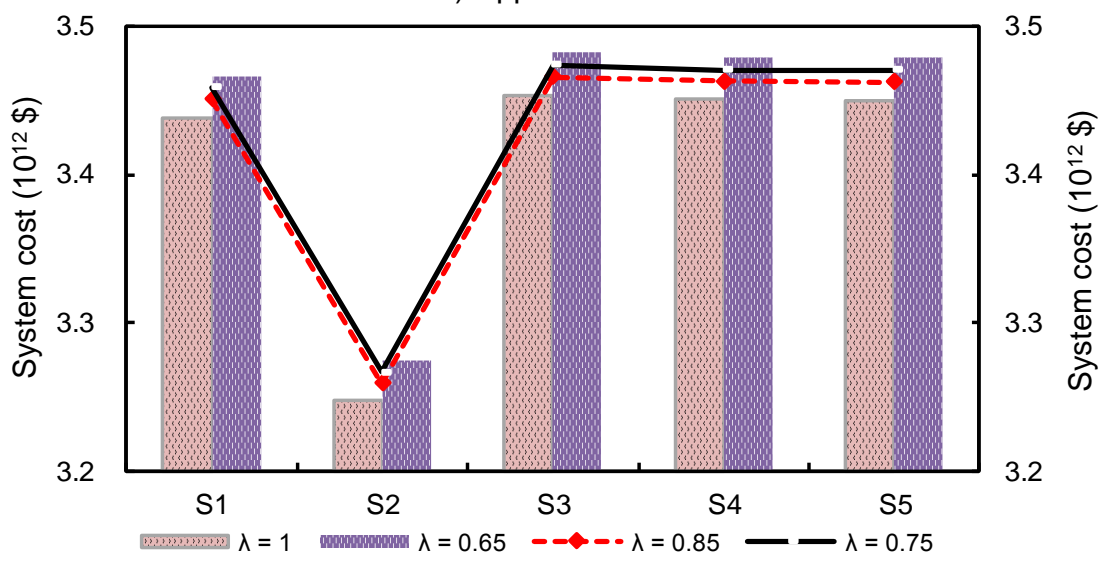

Figure 10. System costs $\left(\$ 10^{12}\right)$ 


$\begin{array}{ll}\text { Abbreviation: } \\ \text { ABM } & \text { agent-based modelling } \\ \text { AIC } & \text { Akaike information criterion } \\ \text { BIC } & \text { Bayesian information criteria } \\ \text { CFIP } & \text { copula-based fuzzy interval-random programming } \\ \text { CO }_{2} & \text { carbon dioxide } \\ \text { CRP } & \text { copula-based random programming } \\ \text { ENA } & \text { ecological network analysis } \\ \text { FPP } & \text { fuzzy possibilistic programming } \\ \text { GDP } & \text { gross domestic product } \\ \text { IESM } & \text { integrated energy system modelling } \\ \text { IO } & \text { input-output } \\ \text { IPP } & \text { interval-parameter programming } \\ \text { LCA } & \text { life cycle assessment } \\ \text { MOP }_{\text {MSE }} & \text { multi-objective programming } \\ \text { NO }_{x} & \text { mean square error } \\ \text { PM } & \text { nitrogen oxides } \\ \text { RMSE } & \text { particulate matter } \\ \text { SDM } & \text { root mean square error } \\ \text { SO } & \text { system dynamic modelling } \\ \text { WEFE }_{\text {WEN }} & \text { sulfur dioxide } \\ & \text { water-energy-food-environment } \\ & \text { water-energy nexus }\end{array}$




\section{Explanations for system coefficients:}

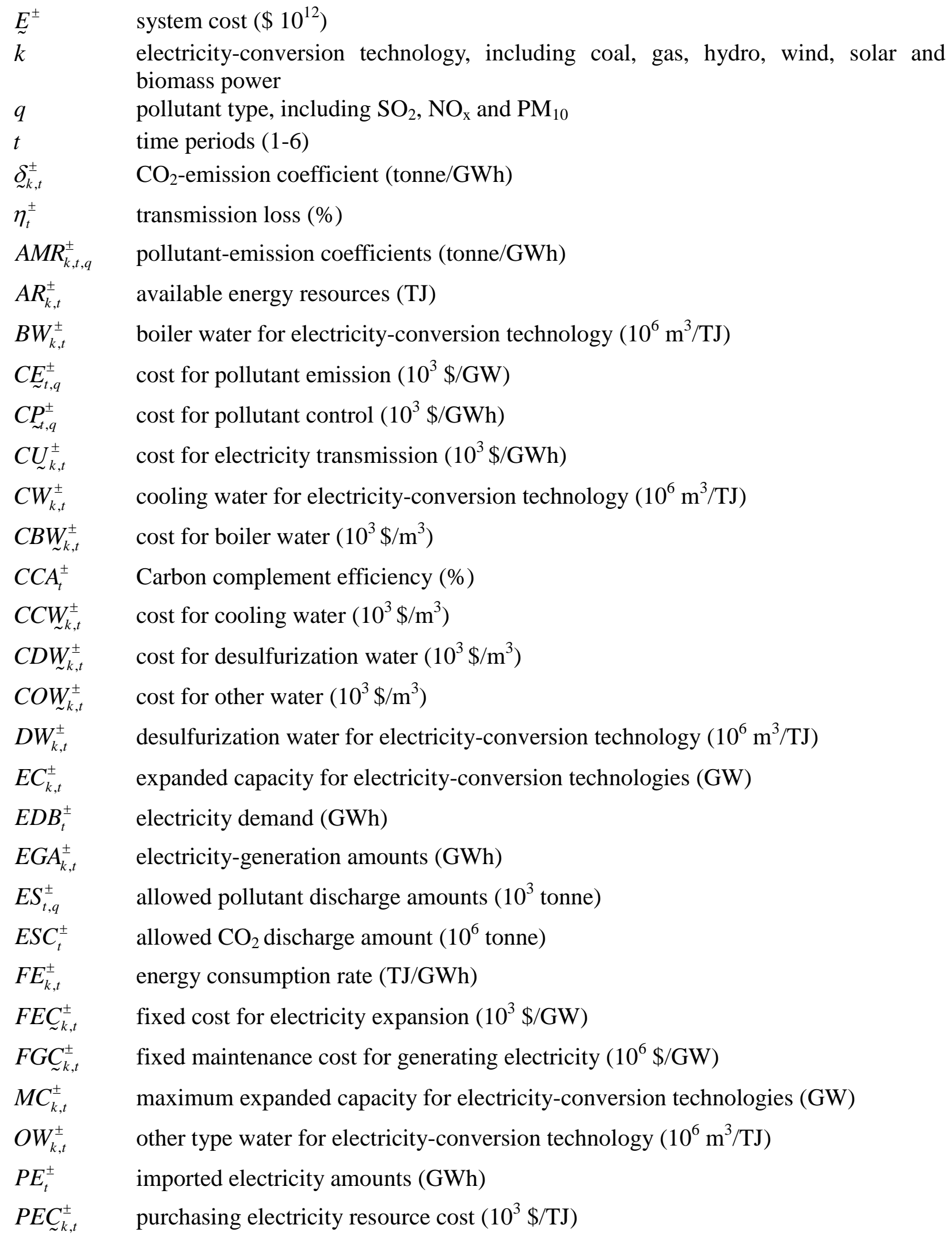


$P E J_{\tau}^{ \pm} \quad$ importing electricity cost $\left(10^{3} \$ / \mathrm{GWh}\right)$

$R C_{k, t}^{ \pm} \quad$ residual capacity for electricity-conversion technologies $(\mathrm{GW})$

$S T_{k, t}^{ \pm} \quad$ service time of electricity-conversion technologies (h)

$S U_{\sim, t}^{ \pm} \quad$ financial subsidy $\left(10^{3} \$ / \mathrm{GWh}\right)$

$T A W_{t}^{ \pm} \quad$ amount of available water resource $\left(10^{6} \mathrm{~m}^{3}\right)$

$T E_{k, t}^{ \pm} \quad$ power-facilities conversion efficiency (\%)

$V E C_{\sim, t}^{ \pm} \quad$ variable cost for electricity expansion $\left(10^{3} \$ / \mathrm{GW}\right)$

$V G C_{\sim, t}^{ \pm} \quad$ variable cost for generating electricity $\left(10^{3} \$ / G W h\right)$

$W D B_{t}^{ \pm} \quad$ water resources demand $\left(10^{6} \mathrm{~m}^{3}\right)$

$Y C_{k, t}^{ \pm} \quad 0-1$ variables for electricity-generation

$Z L_{k, t}^{ \pm} \quad$ power consumption rate (\%) 


\title{
Declaration of Interest Statement

\begin{abstract}
All of the authors have read and approved the paper and it has not been published previously nor is it being considered by any other peer-reviewed journal. No conflict of interest.
\end{abstract}

